\title{
Methane dynamics downstream of a temperate run-of-the-river reservoir
}

\author{
Tonya DelSontro, ${ }^{1,2, a *}$ Karina K. Perez, ${ }^{1}$ Sébastien Sollberger, ${ }^{1,2}$ Bernhard Wehrli ${ }^{1,2}$ \\ ${ }^{1}$ Eawag, Swiss Federal Institute of Aquatic Science and Technology, Kastanienbaum, Switzerland \\ ${ }^{2}$ Institute of Biogeochemistry and Pollutant Dynamics, ETH Zürich, Zürich, Switzerland
}

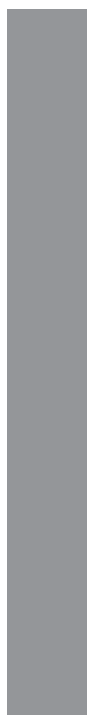

\begin{abstract}
Dams impact a significant portion of the world's rivers, and rivers downstream of the reservoirs created by large dams often emit significant amounts of methane $\left(\mathrm{CH}_{4}\right)$. River $\mathrm{CH}_{4}$ emissions downstream of run-of-theriver (ROR) dams are less well known. We investigated spatial and seasonal $\mathrm{CH}_{4}$ dynamics along a stretch of the Aare River (Switzerland) downstream from a bubbling ROR reservoir. We found that the $\mathrm{CH}_{4}$ horizontally accumulated in this vertically non-stratifying ROR reservoir was consistently transported to the downstream river, but half was lost near a confluence with a tributary. We estimated $\mathrm{CH}_{4}$ diffusion using gas exchange coefficient $(k)$ models that incorporate specific river characteristics and found $\mathrm{CH}_{4}$ emissions were threefold higher upstream of the confluence than downstream. We discuss the use of $\mathrm{CO}_{2}$-derived $k$ models in estimating $k$ for $\mathrm{CH}_{4}$, and investigated it directly using a drifting chamber experiment. While chamber emissions only partly agreed with the $k$ models, the models were robust enough to use in a $\mathrm{CH}_{4}$ mass balance along the river that indicated an overall $\mathrm{CH}_{4}$ loss from the study area. The loss predominantly occurred at the confluence and $>92 \%$ of it could not be accounted for by modelled or measured $\mathrm{CH}_{4}$ emissions. Ultimately, a ROR reservoir that does not form an anoxic, $\mathrm{CH}_{4}$-rich hypolimnion enhanced downstream river $\mathrm{CH}_{4}$ emissions, but to a lesser extent than other systems ( $9 \%$ of total reservoir-associated emissions). Regardless, small ROR dams and river features such as confluences should be considered when measuring, estimating or upscaling river $\mathrm{CH}_{4}$ emissions.
\end{abstract}

The general importance of inland waters in carbon cycling, particularly their role as a significant source of the greenhouse gases methane $\left(\mathrm{CH}_{4}\right)$ and carbon dioxide $\left(\mathrm{CO}_{2}\right)$, is now widely accepted by the scientific community (Cole et al. 2007; Battin et al. 2009; Tranvik et al. 2009; Raymond et al. 2013). Airwater exchange of the carbonic greenhouse gases in rivers is highly relevant for global biogeochemical budgets and for constraining the carbon cycle (Aufdenkampe et al. 2011), especially because a large fraction of terrestrial carbon entering the freshwater continuum via rivers is processed, stored or emitted along route instead of discharged to the oceans (Cole et al.

*Correspondence: tdelsontro@gmail.com

apresent address: Department of Biological Sciences, University of Quebec at Montreal, Montréal, Québec, Canada

Additional Supporting Information may be found in the online version of this article.

Special Issue: Methane Emissions from Oceans, Wetlands, and Freshwater Habitats: New Perspectives and Feedbacks on Climate Edited by: Kimberly Wickland and Leila Hamdan.
2007). Carbon processing can, of course, occur in any freshwater body (lakes, rivers, or streams), but recent evidence suggests that there are differences between the greenhouse dynamics of lakes and fluvial systems (Raymond et al. 2013). Based on the limited studies available that compare aquatic systems in the same landscape, rivers tend to have significantly higher dissolved concentrations and emission rates of $\mathrm{CO}_{2}$ (Teodoru et al. 2009; Raymond et al. 2013; Crawford et al. 2014) and $\mathrm{CH}_{4}$ (Campeau et al. 2014; Selvam et al. 2014; Stanley et al. 2016) than lakes.

While studying rivers and their contribution to the global carbon budget, however, it is important to remember that two thirds of the world's largest rivers (and presumably plenty of small and moderately-sized ones) are fragmented by dams (Nilsson et al. 2005). With that damming comes significant disruptions in the natural carbon flow and processing along the river courses, including flooding of adjacent soils and vegetation (St Louis et al. 2000; Guérin et al. 2008), and massive sediment and carbon retention behind dams (Vörösmarty et al. 2003; Syvitski et al. 2005; Tranvik et al. 2009). One way the new sedimentation regimes behind 
dams impact the biogeochemistry of these freshwaters is by promoting high rates of methanogenesis in carbon-rich, anoxic sediments and areas of flooded vegetation. Ultimately, many of these reservoirs emit significant amounts of $\mathrm{CH}_{4}$ to the atmosphere (St Louis et al. 2000; Tremblay et al. 2005; Barros et al. 2011; Bastviken et al. 2011; Wehrli 2011).

Reservoirs emit $\mathrm{CH}_{4}$ from their surfaces via diffusion and ebullition as well as from the turbulent outflow at or after the turbines in hydroelectric reservoirs (Abril et al. 2005; Tremblay et al. 2005; Guérin et al. 2006). In addition, enhanced $\mathrm{CH}_{4}$ emissions from the rivers downstream of reservoirs have also been attributed to the presence of upstream reservoirs in a few studies (Guérin et al. 2006; Guérin and Abril 2006; Kemenes et al. 2007). The upstream reservoirs in these studies are characterized by relatively large flooded surfaces that produced a water body that stratified, formed an anoxic hypolimnion, and consequently accumulated $\mathrm{CH}_{4}$ that was later transported downstream following dam passage (Guérin et al. 2006; Kemenes et al. 2007; Guérin and Abril 2007). This scenario, however, may not apply to smaller run-of-the-river (ROR) reservoirs as they typically flood less surrounding land, if at all, and are shallow flowthrough systems that may not provide ideal conditions for vertical stratification and anoxia. This remains speculation, however, as not much is yet known about diffusive $\mathrm{CH}_{4}$ emissions downstream of ROR reservoirs.

Measuring diffusive gas emissions from fluvial systems is unfortunately not as straightforward as doing so on lakes and non-flowing water bodies. The most common technique for measuring diffusive emissions on lakes involves an anchored floating chamber (e.g., Vachon et al. 2010; Schubert et al. 2012). While some fluvial studies have used anchored chambers (e.g., Crawford et al. 2013), it is not the best choice for flowing waters as enhanced turbulence near the edges of the chamber will artificially inflate surface gas exchange (Lorke et al. 2015). Therefore, the sampling technique was modified in some studies to allow the chamber to drift with water flow, often still tied to the boat, in order to reduce complications from enhanced turbulence (Guérin et al. 2006; Kemenes et al. 2007; Eugster et al. 2011; Teodoru et al. 2015). Alternatively, a gas tracer such as propane, for example, can also be used to measure gas emission from fluvial systems (Hope et al. 2001).

Gas emission can also be estimated if the gas gradient across the air-water interface and the gas transfer velocity, $k$ (also called the piston velocity) are known (MacIntyre et al. 1995). While measuring the gradient is simple, knowing the true $k$ is not, as it depends highly on the turbulence on both sides of the gradient. A standard model used to estimate $k$ for lakes uses wind speed (e.g., Crusius and Wanninkhof 2003), yet other parameters such as lake size, fetch, or surface waves have also been used as they too impact turbulence and, hence, gas emissions (MacIntyre et al. 1995; Vachon et al. 2010; Vachon and Prairie 2013). Such parameterizations of $k$ in fluvial systems are not as prevalent. Those that exist suggest that relatively easy-to-measure variables can be used to predict $k$, such as river width (Alin et al. 2011), depth, velocity, discharge, and slope (Raymond et al. 2012). However, these parameterizations, which were estimated for $\mathrm{CO}_{2}$ emissions, have not been readily validated by other studies, especially $\mathrm{CH}_{4}$ emission studies.

The importance of estimating or measuring $\mathrm{CH}_{4}$ emissions from rivers downstream of hydropower reservoirs should not be understated as those emissions could be attributed to the upstream reservoir, and potentially further reduce the clean energy status of hydropower (Giles 2006). A notable example is Petit Saut reservoir in French Guyana, where downstream emissions constitute $>60 \%$ of total $\mathrm{CH}_{4}$ flux associated with the reservoir, although the majority of those emissions were due to a weir placed downstream of the dam (Abril et al. 2005). Diffusive only $\mathrm{CH}_{4}$ emissions from rivers downstream of the few South American reservoirs where emissions have been monitored were only equivalent to between 5 and 33\% of the total $\mathrm{CH}_{4}$ emissions from the reservoir surface (Guérin et al. 2006) and an equally low emission contribution was recently found downstream of a subtropical reservoir in Laos (Deshmukh et al. 2016). Despite consistently higher areal diffusive fluxes reported for those downstream rivers relative to their upstream reservoirs, the large surface areas of the reservoirs make the downstream diffusive emissions one of the lesser important $\mathrm{CH}_{4}$ emission pathways. Considering ROR reservoirs flood much less land compared to these large South American reservoirs, it is possible that downstream river $\mathrm{CH}_{4}$ flux is an important emission pathway attributable to a ROR reservoir, although this has yet to be studied.

To this effect, over three campaigns in three seasons, we investigated the $\mathrm{CH}_{4}$ dynamics, specifically emissions, along a portion of the Aare River (Switzerland) downstream from a ROR reservoir known for high $\mathrm{CH}_{4}$ ebullition and a horizontal accumulation of dissolved $\mathrm{CH}_{4}$ towards the dam basin (DelSontro et al. 2010; Eugster et al. 2011). We used the most recent parameterizations for $k$ to estimate $\mathrm{CH}_{4}$ gas exchange and conducted a comparative drifting chamber experiment immediately downstream of the dam. Diffusive $\mathrm{CH}_{4}$ emission estimates, as well as dissolved $\mathrm{CH}_{4}$ transfer along the river, were incorporated into a mass balance to examine $\mathrm{CH}_{4}$ dynamics relative to particular sections of the river, including other those containing additional ROR dams and a tributary inflow. Finally, we assessed the contribution of downstream river emissions to the upstream ROR reservoir.

\section{Methods}

Study site

The Aare River (stream order 6) originates from the Swiss Alps and passes two perialpine lakes and the capital city of Bern before reaching Lake Wohlen, which is a ROR reservoir located on the Swiss plateau $\left(46.966210^{\circ} \mathrm{N}, 7.285693^{\circ} \mathrm{E}\right)$ that 
was constructed in 1920 (more details in DelSontro et al. 2010). The Wohlen dam created a reservoir surface of approximately $2.6 \mathrm{~km}^{2}$ with an average discharge of $122 \mathrm{~m}^{3}$ $\mathrm{s}^{-1}$ (range, 40-400 $\mathrm{m}^{3} \mathrm{~s}^{-1}$ ). After Lake Wohlen, the Aare River runs through a $20 \mathrm{~km}$ long reach segmented by one tributary, the Saane River, and two other ROR dams (Niederried and Aarberg) before entering natural Lake Biel via a heavily channelized section (Fig. 1). The river continues out of Lake Biel to the northeast through several more ROR dams and toward the German border where it enters the Rhine River. Our study area was the $20 \mathrm{~km}$ stretch between Lake Wohlen and Lake Biel, including measurements within Lake Wohlen before the Wohlen dam.

Sampling was conducted in February (winter) and May (spring) of 2012 and in June (summer) of 2013 to cover the most likely time for seasonal variability due to snow melt and filling of the river. Our sampling locations began in Lake Wohlen just before the dam (site 1, Fig. 1). The turbine intakes are located at $10 \mathrm{~m}$ water depth and release only $5 \mathrm{~m}$ lower to the downstream Aare River. Sampling locations continued downstream along the Aare River until just before the entrance of the Saane River (sites 2-6), the only tributary in the $20 \mathrm{~km}$ reach. The Saane River has a mean annual discharge of $\sim 55 \mathrm{~m}^{3} \mathrm{~s}^{-1}$ and was also sampled (site 7). Sampling continued downstream until the Niederried dam (sites 8-11) but only for the summer campaign when we increased the resolution. There is a small wetland associated with the Niederried dam but separated from the channelized main river as it is shallow and not flowing. The river is heavily channelized between sites 9 and 11 .

Downstream of Niederried, the river flows towards the Aarberg dam and becomes increasingly channelized with rip-rap (sites 12-13). The Aarberg dam created no flooded reservoir surface. After Aarberg dam, the river splits into two parts: the original arm with a minor runoff flows northwards, whereas the Hagneck channel diverts the main water masses of the Aare to Lake Biel in order to mitigate peak discharge during extreme flood events. Just before site 14 there is a small canal inflow, the Unterwasserkanal, which carries $20 \mathrm{~m}^{3} \mathrm{~s}^{-1}$ of water that is diverted from the Niederried reservoir through an underground tunnel, and only operates when the Aare River discharge is greater than $190 \mathrm{~m}^{3} \mathrm{~s}^{-1}$ (i.e., only during the spring and summer campaigns in our study). Sites 14-15 were located in the most heavily channelized part of the entire river stretch where water flows through the Hagneck channel. An additional ROR dam forms the Hagneck reservoir, which is located before the Aare enters Lake Biel but our sampling stopped short of this dam. Our study section of the Aare River ranges in depth from $3 \mathrm{~m}$ to $5 \mathrm{~m}$ (Appendix 1).

\section{Environmental variables}

Several physical variables were obtained in order to calculate the $\mathrm{CH}_{4}$ flux and transfer. Daily discharge averages were provided by the Federal Office for the Environment (http:// www.bafu.admin.ch) at the stations of Bern Schönau and Hagneck (both on the Aare River), and Laupen (on the Saane River). Sites 2-6 were assigned the discharge from the Bern Schönau station, which is just a few kilometers upstream of Wohlen dam. The Saane discharge (from the Laupen station) was added to the discharge from sites 2-6 and applied to sites 8-11. The Hagneck station is at the outflow of the Aare River into Lake Biel and thus defined the discharge for the remaining sites 12-15. If the Unterwasserkanal was flowing then $20 \mathrm{~m}^{3} \mathrm{~s}^{-1}$ was subtracted from discharge for sites 12 and 13 .

River velocity was measured using a sound velocity probe (Hoentzsch NT-403) and depth was taken with a handheld sonar (UWiTEC). Wind speeds were obtained through the Federal Office of Meteorology from the most nearby stations (http://www.meteoswiss.admin.ch). Slope was taken from the Federal Office of Topography's online topographic maps (http://www.swisstopo.admin.ch/). A conductivitytemperature-depth (CTD; Sea and Sun Technology, Germany) probe was used for in situ temperature measurements.

\section{Dissolved $\mathrm{CH}_{4}$ sampling and analysis}

Sample water was collected in duplicate serum bottles (117 $\mathrm{mL}$ ) bubble free and poisoned with $\mathrm{CuCl}$ to prevent $\mathrm{CH}_{4}$ oxidation. Samples were stored in a cold room until analysis. The headspace method was used to estimate dissolved $\mathrm{CH}_{4}$ concentration by injecting a $30 \mathrm{~mL} \mathrm{~N}$ headspace into the samples and equilibrating them for half an hour in a water bath following ten minutes of exposure to a sonic bath. The gas concentration in the headspace was measured via a gas chromatograph equipped with a flame ionization detector (Mc Allufile 1979). Henry's constant was used to calculate the dissolved $\mathrm{CH}_{4}$ concentrations in the water at sampling temperatures. Variability of duplicates was $<5 \%$ and the average of duplicates was used for analyses.

Within Lake Wohlen (site 1 ; Fig. 1), samples were taken in the water column at a $5 \mathrm{~m}$ depth resolution $(0,5,10$, and $15 \mathrm{~m})$. Only surface samples were taken at the remaining sites along the river. Weather and technical difficulties prevented sampling at a few sites during the 2012 samplings, and recognition of some interesting patterns prompted a higher resolution survey in summer 2013.

\section{$k_{\mathrm{CH} 4}$ and gas exchange calculations}

Gas exchange can be measured via floating chambers (e.g., Guérin et al. 2007) or estimated as the product of the gas exchange velocity ( $k$ in $\mathrm{m} \mathrm{d}^{-1}$ ) and the supersaturation of the surface of the water body relative to atmospheric equilibration, $\left[C_{\mathrm{w}}-C_{\text {eq }}\right]$, (e.g., Crusius and Wanninkhof 2003):

$$
F=k *\left(C_{\mathrm{w}}-C_{\mathrm{eq}}\right)
$$

where $C_{\mathrm{w}}$ is the gas concentration in the water and $C_{\mathrm{eq}}$ is the gas concentration of surface water in equilibrium with 


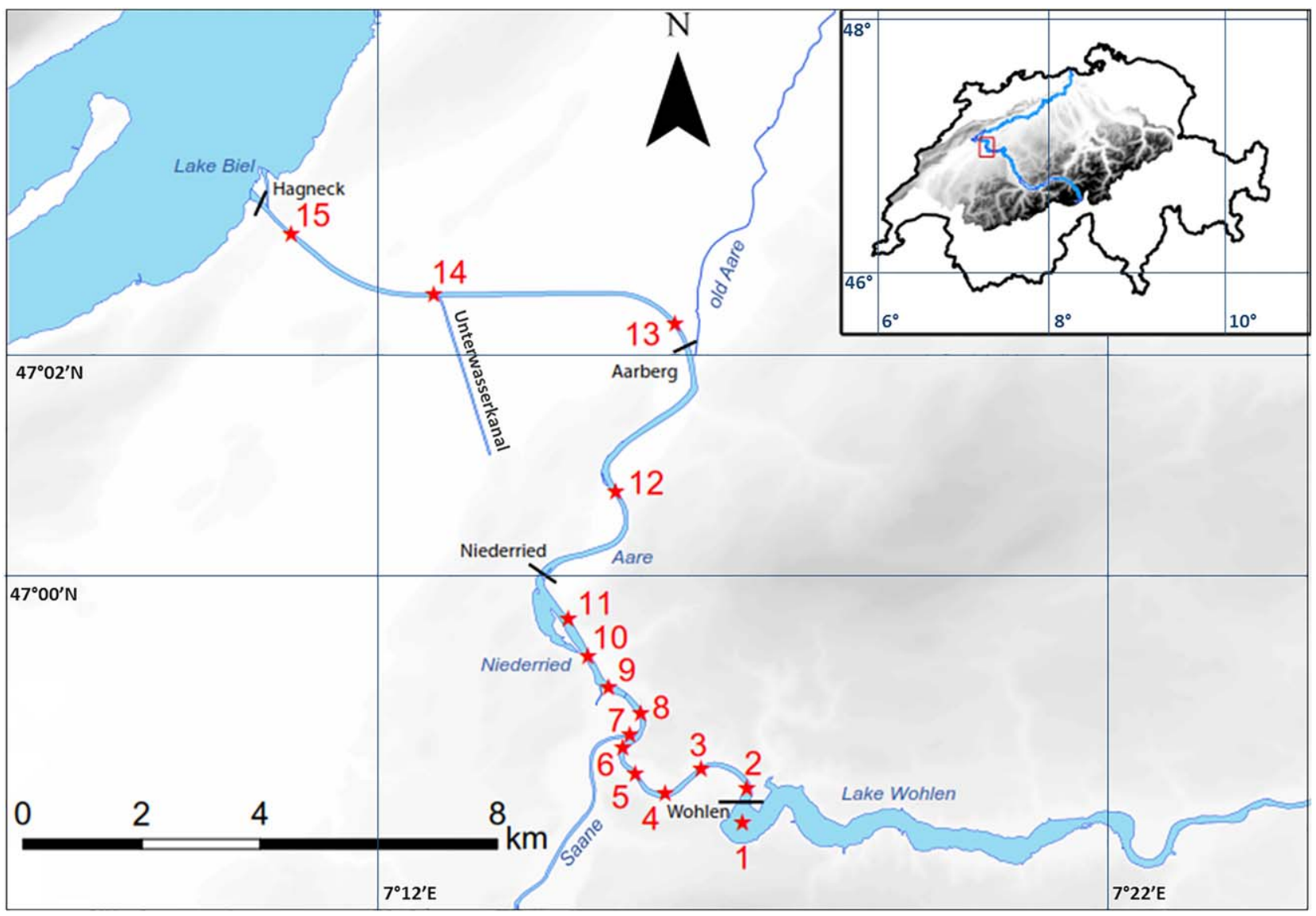

Fig. 1. Map of the Aare River watershed in Switzerland (inset) and a more detailed map of the study sites along the river. Sampling sites are indicated by a numbered star, and dams are named and shown by a black bar. [Color figure can be viewed at wileyonlinelibrary.com]

the atmosphere, here calculated according to Wiesenburg and Guinasso (1979) using an atmospheric $\mathrm{CH}_{4}$ concentration of $1803 \mathrm{ppb}$ (Ciais et al. 2013). Lake Wohlen diffusive flux was calculated using a wind-dependent $k$ model for low wind speeds (Crusius and Wanninkhof 2003). In rivers, we used $k$ models that were empirically derived from two different river studies for $\mathrm{CO}_{2}$ emissions: one based on floating chamber measurements in various streams and rivers of the Amazon and Mekong river systems (Alin et al. 2011), and the other based on a metadata analysis of $>560$ gas tracer experiments conducted on North American streams and rivers (Raymond et al. 2012). We used the Alin et al. (2011) model for rivers less than $100 \mathrm{~m}$ wide (which is true for our study section of the Aare River) and all of the Raymond et al. (2012) models (Table 1) to calculate gas exchange as various functions of depth, velocity, slope and discharge, which were all measured during sampling (depth and velocity) or obtained from a database (slope and discharge).

All of the models described above were developed for $\mathrm{CO}_{2}$ normalized to a Schmidt number (Sc) of 600, which represents the viscosity-diffusivity ratio of $\mathrm{CO}_{2}$ at $20^{\circ} \mathrm{C}$.
Table 1. $k_{600}$ models from the literature used for gas exchange estimates.

\begin{tabular}{|c|c|}
\hline No & $k_{600}$ model equations \\
\hline R1 & {$[V * S]^{0.89 \pm 0.020} *[D]^{0.54 \pm 0.030} *[5037 \pm 604]$} \\
\hline $\mathrm{R} 2$ & {$[5937 \pm 606] *\left[1-2.54 \pm 0.223 * F r^{2}\right] *\lceil V * S\rceil^{0.89 \pm 0.017} *\lceil D\rceil^{0.58 \pm 0.027}$} \\
\hline R3 & {$[1162 \pm 192] * S^{0.77 \pm 0.028} * V^{0.85 \pm 0.045}$} \\
\hline R4 & $\lceil V * S]^{0.76 \pm 0.027} *[951.5 \pm 144]$ \\
\hline R5 & {$[V * S] *[2841 \pm 107]+\lceil 2.02 \pm 0.209\rceil$} \\
\hline R6 & {$[929 \pm 141] * V S^{0.75 \pm 0.027} * Q^{0.011 \pm 0.016}$} \\
\hline R7 & {$[4725 \pm 445] *\lceil V * S\rceil^{0.86 \pm 0.016} *\lceil Q\rceil^{-0.14 \pm 0.012} *\lceil D\rceil^{0.66 \pm 0.029}$} \\
\hline $\mathrm{Aa}$ & $4.46+7.11 U_{10}$ When Width is $>100 \mathrm{~m}$ \\
\hline $\mathrm{Ab}$ & $13.82+0.35 \mathrm{~V}$ When Width is $<100 \mathrm{~m}$ \\
\hline
\end{tabular}

$V$ is velocity $\left(\mathrm{m} \mathrm{s}^{-1}\right) ; D$ is depth $(\mathrm{m}) ; S$ is slope; $Q$ is discharge $\left(\mathrm{m}^{3} \mathrm{~s}^{-1}\right)$; $U_{10}$ is wind speed at $10 \mathrm{~m}$ height $\left(\mathrm{m} \mathrm{s}^{-1}\right)$. Equations R1-R7 from Raymond et al. (2012) and Equations Aa and Ab from Alin et al. (2011).

Thus, gas exchange results from the models are referred to as " $k_{600}$." The $k$ for $\mathrm{CH}_{4}$ (hereafter referred to as " $k_{\mathrm{CH} 4}$ ") was calculated from the $k_{600}$ from $\mathrm{CO}_{2}$ models using the following relationship (MacIntyre et al. 1995): 


$$
\frac{k_{600}}{k_{\mathrm{CH} 4}}=\left(\frac{600}{\mathrm{Sc}_{\mathrm{CH} 4}}\right)^{n}
$$

where $\mathrm{Sc}_{\mathrm{CH} 4}$ is the $\mathrm{Sc}$ for $\mathrm{CH}_{4}$ calculated according to the equation and coefficients given in Wanninkhof (2014), while the exponent, $n$, is a constant depending on the roughness of the water surface (Jähne et al. 1987). For the low wind speeds of Lake Wohlen (Appendix 2), we set $n=-2 / 3$ following Jähne et al. (1987). For river sites, we followed the procedure of Borges et al. (2004) and set $n=-1 / 2$, which better reflects enhanced turbulence in rivers due to water velocity and shallow depths.

\section{Drifting chamber survey}

During the summer campaign a drifting chamber survey was conducted to directly measure diffusive $\mathrm{CH}_{4}$ fluxes between the Wohlen and Niederried ROR dams, including across the Saane River inflow. Chambers consisted of buckets covered with aluminum foil and surrounded by a foam skirt for floatation with less than $5 \mathrm{~cm}$ of the bucket below the water surface. A silicon tube with a stopcock was fitted to the top of the chambers for sampling. Two chambers (for duplicate samples) were attached to the side of the boat and measurements were made between sites while drifting downstream; thus $\mathrm{CH}_{4}$ fluxes were measured from site 2-4, 4-6, 6-9, and 9-11.

Samples were taken at the start and end of deployment, which was approximately 12-17 min long depending on the distance between locations. Ten milliliters of gas was first removed from the chamber to clean the tube of any unmixed gas. Then, $30 \mathrm{~mL}$ of gas was collected and injected into a $60 \mathrm{~mL}$ vial prefilled with an oversaturated $\mathrm{NaCl}$ solution to prevent gas exchange between the injected gas and the liquid phase. Samples were stored upside down in the cool room until analyzed using a GC-FID. An air sample was taken at the start of each deployment to account for the starting gas concentration in the chamber. Fluxes were calculated according to the following:

$$
F=\frac{d \mathrm{CH}_{4}}{d t} * v / s
$$

where $\frac{d \mathrm{CH}_{4}}{d t}$ was the change of $\mathrm{CH}_{4}$ in the chamber per unit of time (nmol $\mathrm{L}^{-1} \mathrm{~h}^{-1}$ ) found via the difference between the atmospheric $\mathrm{CH}_{4}$ concentration and accumulated $\mathrm{CH}_{4}$ at the end of the deployment, $v(\mathrm{~L})$ is the volume of the chamber, and $s\left(\mathrm{~m}^{2}\right)$ is the chamber surface area at water level. Using the $\mathrm{CH}_{4}$ flux measurement from the chamber and the $\mathrm{CH}_{4}$ concentration in the water column, we solved for the chamber $k_{\mathrm{CH} 4}$ via Eq. 1 .

\section{Mass balance approach}

We used a mass balance approach to investigate $\mathrm{CH}_{4}$ mass transfer along the Aare River study area and to identify how particular features such as dams or tributaries would affect the $\mathrm{CH}_{4}$ dynamics along the river. Mass transfer (units, $\mathrm{g} \mathrm{CH}_{4} \mathrm{~d}^{-1}$ ) at any one location is the product of the $\mathrm{CH}_{4}$ concentration $\left(\mathrm{g} \mathrm{m}^{-3}\right)$ and the discharge rate $\left(\mathrm{m}^{3} \mathrm{~d}^{-1}\right)$. The mass flux of the one tributary was incorporated into the mass balance calculations downstream of site 6 . We calculated mass transfer in five sections of the river: (1) sites 1-2 containing Wohlen dam, (2) sites 2-6, (3) between sites 6 and 8 that contain the Saane River inflow, whose addition was taken into account, (4) sites 8-13 containing the ROR dams, Niederried and Aarberg, and (5) sites 13-15. The basic mass balance for a section of river without tributaries follows the approach of de Angelis and Scranton (1993):

$$
M_{\text {in }}+M_{\text {add }}-M_{\text {diff }}-M_{\text {oxi }}=M_{\text {out }}
$$

where the amount of $\mathrm{CH}_{4}$ leaving the section $\left(M_{\text {out }}\right.$; last site of section) is equal to the amount of dissolved $\mathrm{CH}_{4}$ entering the section via the main inflow (first site of section) and any major tributaries $\left(M_{\text {in }}\right)$ plus $\mathrm{CH}_{4}$ released from additional sources during its course (i.e., sediment production or advection from adjacent soils; $M_{\text {add }}$ ) minus the amount of $\mathrm{CH}_{4}$ lost via diffusion to the atmosphere $\left(M_{\text {diff }}\right)$ and consumed via oxidation in the water column $\left(M_{\text {oxi }}\right)$. We measured $M_{\text {in }}$ and $M_{\text {out }}$ directly. $M_{\text {diff }}$ was estimated using the diffusive flux calculated from dissolved $\mathrm{CH}_{4}$ concentrations and the $k_{600}$ models, and the area of the river section in which the mass balance applied. The river section areas were calculated using topographic maps in GIS.

The two unknowns of the mass balance were $M_{\text {add }}$ and $M_{\text {oxi }}$, which were isolated on one side of the equation and called $\Delta M\left(=M_{\text {add }}-M_{\text {oxi }}\right)$ so that:

$$
\Delta M=M_{\text {out }}-M_{\text {in }}+M_{\text {diff }}
$$

We did not measure $\mathrm{CH}_{4}$ oxidation or additional $\mathrm{CH}_{4}$ sources (i.e., internal $\mathrm{CH}_{4}$ production or riparian inputs); therefore, a positive $\Delta M$ suggested that there was a net input of $\mathrm{CH}_{4}$ (from sediments or other sources) in that river section, while a negative result indicated an overall $\mathrm{CH}_{4}$ loss with oxidation exceeding inputs from sediments or soils into the section.

\section{Results}

\section{Environmental variables}

Slopes along the river sections were mostly shallow (on average $<0.0005$ ) as elevation changed on average by $\sim 1 \mathrm{~m}$ over several hundred meters of river distance, except for across dams. All constant site details are provided in Appendix 1 and campaign specific details are documented in Appendix 2. Water temperature along the river during the campaigns ranged from $4^{\circ} \mathrm{C}$ to $14^{\circ} \mathrm{C}$ and wind speeds averaged $1.4 \mathrm{~m} \mathrm{~s}^{-1}, 2.1 \mathrm{~m} \mathrm{~s}^{-1}$, and $0.8 \mathrm{~m} \mathrm{~s}^{-1}$ during the winter, spring and summer campaigns, respectively. Water velocity ranged from $0.1 \mathrm{~m} \mathrm{~s}^{-1}$ to $1.9 \mathrm{~m} \mathrm{~s}^{-1}$ and daily discharge 
varied between $38 \mathrm{~m}^{3} \mathrm{~s}^{-1}$ during the winter campaign and $331 \mathrm{~m}^{3} \mathrm{~s}^{-1}$ during the summer campaign.

\section{Spatiotemporal variability of dissolved $\mathrm{CH}_{4}$}

Dissolved $\mathrm{CH}_{4}$ concentrations in Lake Wohlen ranged from $0.48 \mu \mathrm{M}$ to $0.77 \mu \mathrm{M}$ during the spring and summer campaigns (Fig. 2a). Lake Wohlen was not sampled during winter as it was still covered in ice. The water column of Lake Wohlen was well-mixed during each campaign with no more than a $0.09 \mu \mathrm{M}$ difference between the surface and $15 \mathrm{~m}$ depth. During the spring campaign, we sampled three different locations of the dam basin and all the sites were quite similar; therefore, only one location was sampled during the summer 2013 campaign.

In all three campaigns, the dissolved $\mathrm{CH}_{4}$ variability along the river followed the same trend (Fig. 2b, Appendix 2). Dissolved $\mathrm{CH}_{4}$ concentrations remained similar to Lake Wohlen surface concentrations for $\sim 4 \mathrm{~km}$ downstream (sites 2-6 with $\sim 1.3 \mu \mathrm{M}, 0.5 \mu \mathrm{M}$, and $1.3 \mu \mathrm{M}$ for winter, spring and summer campaigns, respectively; Fig. 2b). In each campaign, concentrations just after the Saane River (site $8 ; \sim 0.4 \mu \mathrm{M}$, $0.1 \mu \mathrm{M}$, and $0.2 \mu \mathrm{M}$ for winter, spring, and summer campaigns, respectively) were roughly one third of the concentration at site 6 upstream of the Saane, and concentrations remained low for the remaining $16 \mathrm{~km}$ of river. The confluence of the Aare and Saane Rivers thus marked the most substantial change in dissolved $\mathrm{CH}_{4}$ along the study area with higher $\mathrm{CH}_{4}$ concentrations upstream of the confluence (seasonal mean $=0.76 \mu \mathrm{M}, \mathrm{SD}=0.4$ ) than downstream (seasonal mean $=0.28 \mu \mathrm{M}, \mathrm{SD}=0.05 ; t=1.98$, n.s.). The Saane River was sampled during the spring and summer campaigns when it was deep enough to navigate and had substantially lower $\mathrm{CH}_{4}$ concentrations than the Aare $(<0.1 \mu \mathrm{M}$ in both campaigns; site 7).

\section{$\boldsymbol{k}_{600}$ models, $\boldsymbol{k}_{\mathrm{CH} 4}$ and diffusive $\mathrm{CH}_{4}$ flux}

The $k_{600}$ model results for Lake Wohlen varied from $0.9 \mathrm{~m}$ $\mathrm{d}^{-1}$ to $1.8 \mathrm{~m} \mathrm{~d}^{-1}$ and were generally lower than the Aare River results (range, 0.3-15.1 $\mathrm{m} \mathrm{d}^{-1}$; average, $3.7 \mathrm{~m} \mathrm{~d}^{-1}$ ). The Saane River, which is much shallower than the Aare River and one stream order lower, had the highest $k_{600}$ values (range, 3.4-61.4 $\mathrm{m} \mathrm{d}^{-1}$; average, $22.3 \mathrm{~m} \mathrm{~d}^{-1}$ ). The $k_{\mathrm{CH} 4}$ results expectedly followed similar trends as that of the $k_{600}$ results, but were approximately 23\% lower following the conversion using Eq. 2.

The $k_{\mathrm{CH} 4}$ calculated for Lake Wohlen (site 1, Fig. 3) was much lower $\left(0.6-1.3 \mathrm{~m} \mathrm{~d}^{-1}\right)$ than that for all river sites, especially site 7 in the Saane River which was the highest of all sites in spring and summer (Fig. 3, Appendix 3). The variability in $k_{\mathrm{CH} 4}$ values increased from the winter campaign through the spring and summer campaigns as evidenced by the changing Y-scale in Fig. 3, presumably because of model parameters like river velocity increasing throughout the seasonal campaigns (Table 1 and Appendix 2). During the winter campaign, all piston velocities along the river (sites 2-6 and $8-15$ ) were below $4 \mathrm{~m} \mathrm{~d}^{-1}$, but the spring and summer campaigns exhibited maximum values in the range of 10 $12 \mathrm{~m} \mathrm{~d}^{-1}$. Models R1, R2, and R7, which were the only models to consider depth as a variable, resulted in the highest values for spring and summer campaign data. Models R3, R4, R5, and R6 produced similar results to each other. Model Ab resulted in approximately the same value for all campaigns as it contained only one linearly related variable in the model. Model Ab, therefore, produced some of the highest results during the winter campaign, but became more similar to the lower value results during the spring and summer campaigns. Remarkably, the $k_{\mathrm{CH} 4}$ values derived from the drifting chamber fluxes during the summer campaign fell within the variability of all models across most of the sites over which the chambers drifted (Fig. 3c), except for sites 9-11 where chamber $k_{\mathrm{CH} 4}$ was slightly higher. In the Saane River, the $k_{600}$ model results varied more with individual model values up to $28 \mathrm{~m}$ and $49 \mathrm{~m} \mathrm{~d}^{-1}$ for the spring and summer campaigns, respectively.

Diffusive $\mathrm{CH}_{4}$ fluxes from Lake Wohlen, Aare, and Saane River surfaces were calculated using the average of the respective $k_{\mathrm{CH} 4}$ models and the measured dissolved $\mathrm{CH}_{4}$ concentrations. In the Aare River, flux estimates followed dissolved concentration trends with higher rates upstream (sites 2-6) than downstream for all seasons (sites 8-15; Fig. 4, Appendix 4). Lowest fluxes were observed during the winter campaign with an average rate of $21 \mathrm{mg} \mathrm{CH}_{4} \mathrm{~m}^{-2} \mathrm{~d}^{-1}$ upstream of the Saane River and $7 \mathrm{mg} \mathrm{CH}_{4} \mathrm{~m}^{-2} \mathrm{~d}^{-1}$ downstream of that tributary. During the spring campaign, upstream fluxes were similar to those during the winter campaign, except for at site 6 where some high individual model values (>60 mg $\mathrm{CH}_{4} \quad \mathrm{~m}^{-2} \mathrm{~d}^{-1}$ from models $\mathrm{R} 1$ and $\mathrm{R} 2$ ) resulted in an average flux of $34 \mathrm{mg} \mathrm{CH}_{4} \mathrm{~m}^{-2} \mathrm{~d}^{-1}$. Downstream during the spring campaign, average fluxes were $<15 \mathrm{mg} \mathrm{CH}_{4} \mathrm{~m}^{-2} \mathrm{~d}^{-1}$. Fluxes were highest during the summer campaign with the upstream section averaging $39 \mathrm{mg} \mathrm{CH} \mathrm{m}^{-2} \mathrm{~d}^{-1}$ and some individual models producing values over $80 \mathrm{mg} \mathrm{CH}_{4} \mathrm{~m}^{-2} \mathrm{~d}^{-1}$. Downstream summer campaign fluxes averaged $15 \mathrm{mg} \mathrm{CH}_{4} \mathrm{~m}^{-2} \mathrm{~d}^{-1}$. Lake Wohlen diffusive emissions were relatively low ranging from 6 to $10 \mathrm{mg}$ $\mathrm{CH}_{4} \mathrm{~m}^{-2} \mathrm{~d}^{-1}$ over the seasons (Fig. 4, Appendix 4). Saane River flux estimates fell between values for the upstream and downstream Aare River sections, averaging 15 and $27 \mathrm{mg}$ $\mathrm{CH}_{4} \mathrm{~m}^{-2} \mathrm{~d}^{-1}$ in spring and summer, respectively.

Results from the drifting chamber survey during the summer campaign followed the same general pattern as the modelled fluxes with emissions increasing towards the Saane River inflow and decreasing downstream of the inflow, but only two of the four chamber measurements fell within the range of the model results (Fig. 4c). At the sites just after Wohlen dam (sites 2-4), chamber fluxes were nearly identical to the average modelled flux $\left(41 \pm 3\right.$ and $43 \mathrm{mg} \mathrm{CH}_{4} \mathrm{~m}^{-2}$ $\mathrm{d}^{-1}$ for chamber and modelled, respectively). The average chamber flux from sites 4-6 before the Saane inflow 

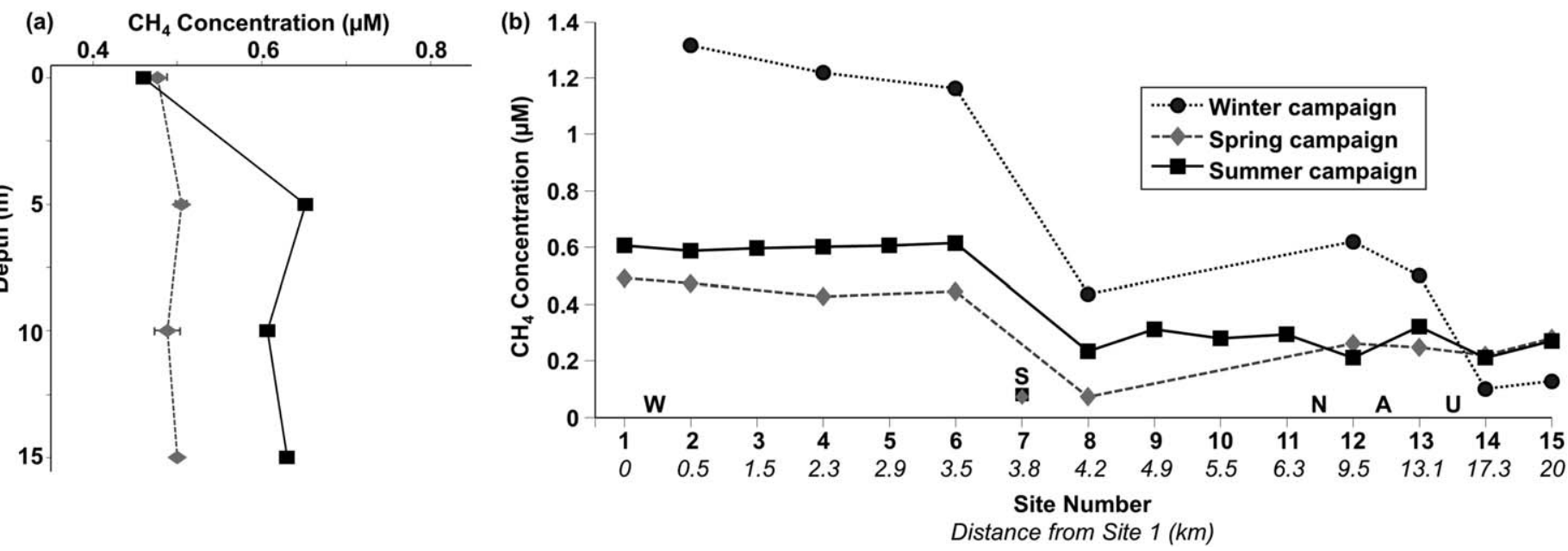

Fig. 2. (a) Dissolved $\mathrm{CH}_{4}$ concentrations $(\mu \mathrm{M})$ in the water column of Lake Wohlen during the spring (May, diamonds) and summer (June, squares) campaigns (winter not sampled due to ice). Spring profile was averaged from three sites (standard deviations shown), but only one site was measured in summer. (b) $\mathrm{CH}_{4}$ concentrations in Aare River surface water from within Lake Wohlen (site 1) and downstream during three campaigns. Sample sites shown in Figure 1. Distance from site $1(\mathrm{~km})$ given for each site. W, N, A, and U mark locations of Wohlen, Niederried, Aarberg dams, and the Unterwasserkanal, respectively. S marks the Saane River site whose concentrations are also shown.
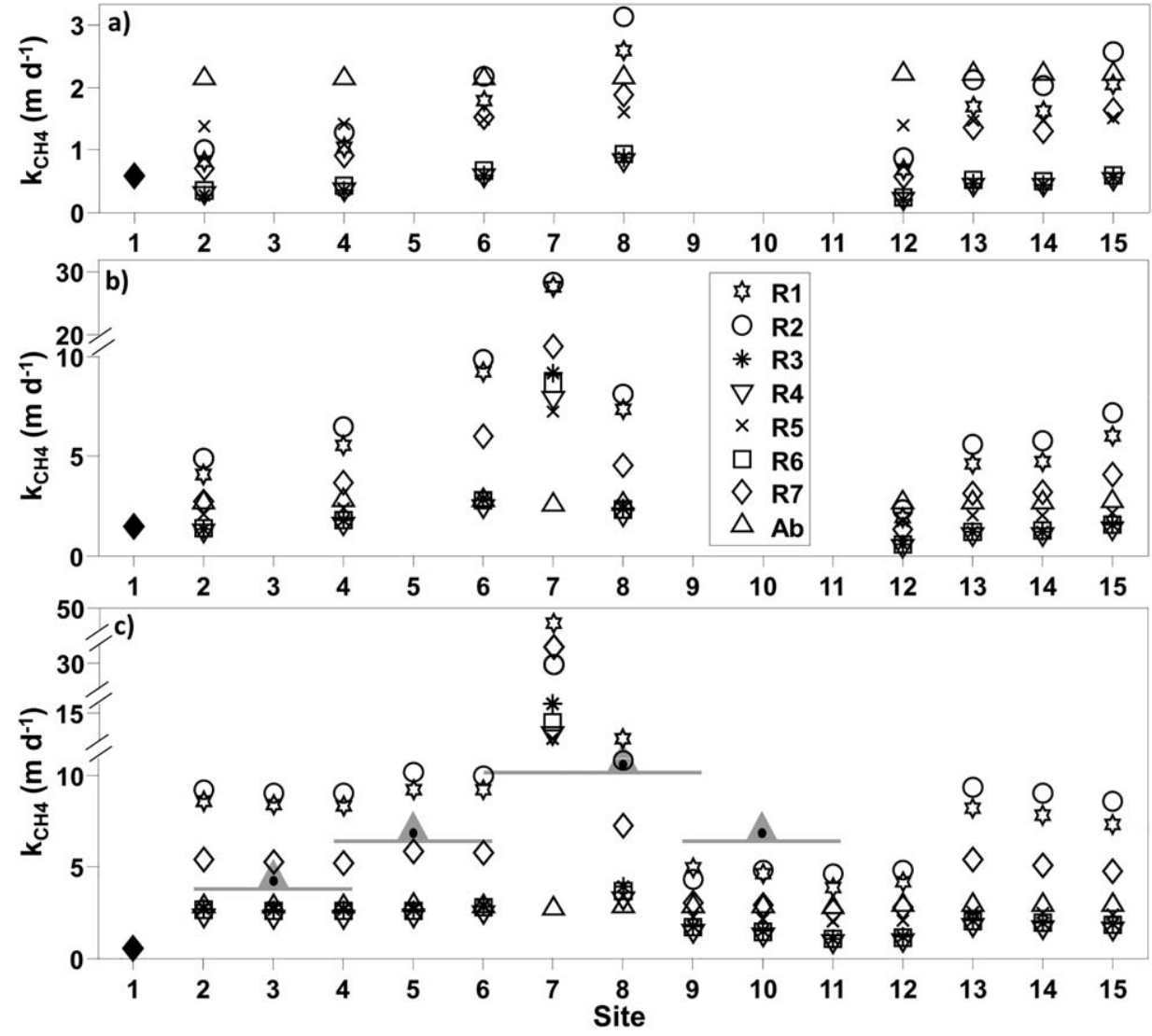

Fig. 3. $k_{\mathrm{CH} 4}$ model results at all relevant sites for campaigns in (a) winter, (b) spring, and (c) summer using $k_{600}$ equations from Raymond et al. (2012) and Alin et al. (2011) (see Table 1). Black triangles for site 1 calculated using wind-dependent $k_{600}$ model from Crusius and Wanninkhof (2003). In (c), $k_{\mathrm{CH} 4}$ values calculated from drifting chamber experiment shown as gray triangles with black dot and with lines covering the sites over which drifting occurred. 

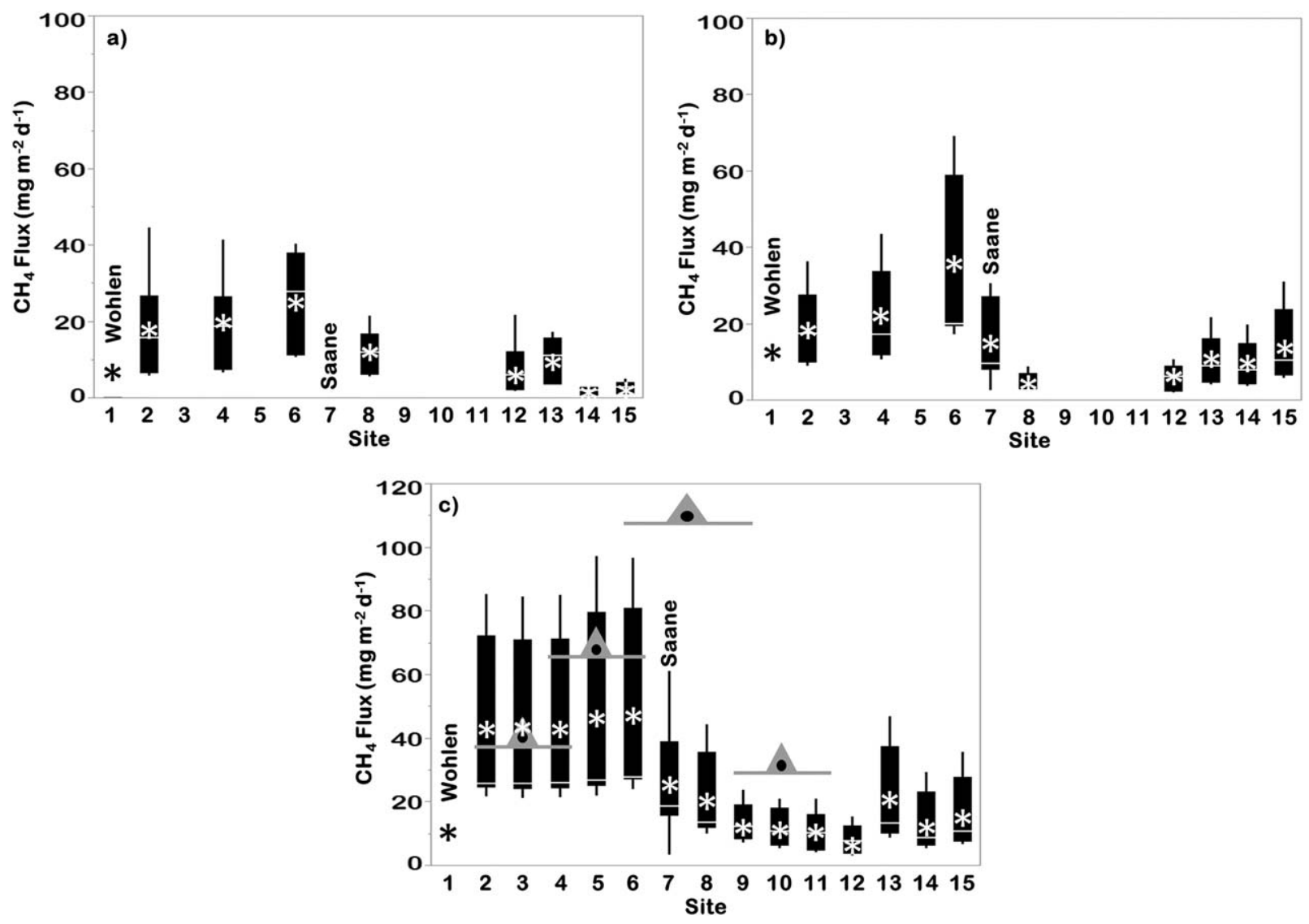

Fig. 4. Box plots showing $\mathrm{CH}_{4}$ fluxes ( $\mathrm{mg} \mathrm{CH}_{4} \mathrm{~m}^{-2} \mathrm{~d}^{-1}$ ) calculated with all $k_{600}$ models for (a) winter, (b) spring, and (c) summer campaigns. Boxes outline the $25 \%$ and $75 \%$ quantiles and whiskers show minimum and maximum values. White lines represent the median and white asterisks represent the average. Wohlen reservoir flux calculated using a wind-dependent $k_{600}$ (black asterisk, site 1). In (c), gray triangles with black dot represent drifting chamber $\mathrm{CH}_{4}$ flux results with the line covering the sites over which drifting occurred. Note the different $\mathrm{Y}$-axis scale in this panel.

$\left(68 \pm 11 \mathrm{mg} \mathrm{CH}_{4} \mathrm{~m}^{-2} \mathrm{~d}^{-1}\right)$ was $>30 \%$ higher than the average model result $\left(46 \mathrm{mg} \mathrm{CH}_{4} \mathrm{~m}^{-2} \mathrm{~d}^{-1}\right)$, but fell within the modelled flux variability (Fig. 4c). Across the Saane River inflow (sites 6-9), however, the average chamber result $\left(110 \pm 31 \mathrm{mg} \mathrm{CH}_{4} \mathrm{~m}^{-2} \mathrm{~d}^{-1}\right)$ was four times the average modelled fluxes from the corresponding sites. When compared to only site 6, the chamber measurement across the Saane confluence was slightly higher than the maximum model result (model R2 $=98.1 \mathrm{mg} \mathrm{CH} \mathrm{m}^{-2} \mathrm{~d}^{-1}$; Appendix 4). Similarly, the chamber result from sites 9-11 below the Saane inflow $\left(31 \pm 4 \mathrm{mg} \mathrm{CH}_{4} \mathrm{~m}^{-2} \mathrm{~d}^{-1}\right)$ was double the average of the modelled fluxes (Fig. 4c), but chamber measurements at these sites were lower than all other chamber measurements, a trend also observed in the $k_{\mathrm{CH} 4}$ model results.

\section{$\mathrm{CH}_{4}$ mass balance}

The mass balance results, $\Delta M$ for $\mathrm{CH}_{4}\left(\mathrm{~kg} \mathrm{~d}^{-1}\right)$, for the five river sections are shown in Fig. 5. The bar represents $\Delta M$ when diffusion was calculated using the average of all $k_{600}$ models for the piston velocity, while the error bars represent $\Delta M$ when the maximum and minimum $k_{600}$ was used to calculate diffusion in the mass balance. As per Eq. 5, a positive value indicates an additional source of $\mathrm{CH}_{4}$ rather than an oxidative sink, and vice versa for a negative value.

In general, the spring (light grey bars) and summer (white bars) campaigns were spatially similar in terms of $\mathrm{CH}_{4}$ transfer, beginning with little change occurring at Wohlen dam or immediately downstream along sites 2-6 (Fig. 5). Both campaigns experienced the most significant change, which was a $\mathrm{CH}_{4}$ loss, at the Saane tributary section, followed by a $\mathrm{CH}_{4}$ gain in the section containing two ROR dams. In the final section, there was a $\mathrm{CH}_{4}$ gain during the spring campaign, but a loss observed during the summer campaign. During the winter campaign (dark grey bars), little change in $\mathrm{CH}_{4}$ occurred in the first few sections, including the Saane tributary section. There was a small $\mathrm{CH}_{4}$ gain in the section containing the two ROR dams followed by the winter's most significant change in the last section. The error bars in Fig. 5 indicate that using the various $k_{600}$ models would not impact the overall trends or magnitudes of $\Delta M$, except for some cases when $\Delta M$ was close to zero such as across upstream sites 2-6 during the spring campaign, or in the longer sections (i.e., the last two sections).

The three main terms of the mass balance ( $\left.M_{\mathrm{in}}, M_{\mathrm{out}}, M_{\mathrm{diff}}\right)$ and the result $(\Delta M)$ for each section during each campaign 


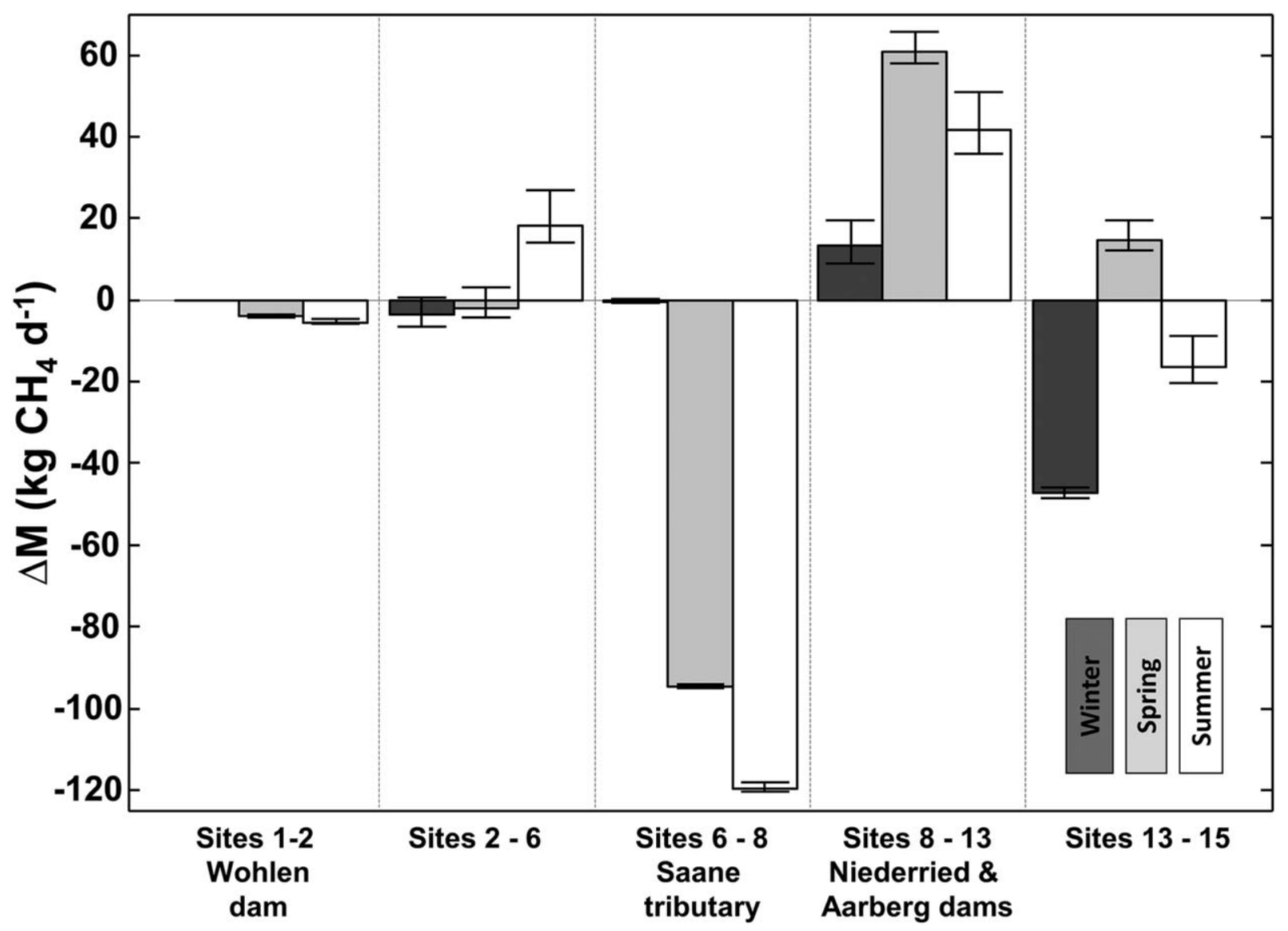

Fig. 5. Mass balance result, $\Delta M=M_{\text {add }}-M_{\text {oxi, }}$ for each section during three campaigns with diffusion calculated using average $k_{600}$ from all models. Error bars show the minimum and maximum $\Delta M$ possible using individual models instead of average.

are compared in Table 2, along with the contribution of gas exchange to $\mathrm{CH}_{4}$ loss if a loss occurred. In the section containing the confluence of the Aare and Saane Rivers, the biggest loss occurred during the spring and summer campaigns, of which diffusion only accounted for about $1 \%$ of the total observed loss, thus suggesting that an important additional sink was needed to close the balance. Similarly, diffusion accounted for only $4 \%$ of the $\mathrm{CH}_{4}$ loss in the last section during the winter campaign, where the largest $\mathrm{CH}_{4}$ transfer occurred. Surface diffusive contributions in other negative $\Delta \mathrm{M}$ sections ranged from $10 \%$ to $75 \%$ for all campaigns. Overall, total mass transfer via surface diffusion along the study area increased from the winter campaign through the spring and summer campaigns (Table 2). Finally, there was a net loss of $\mathrm{CH}_{4}$ (i.e., negative $\Delta M$ ) from the entire study area during each campaign with $26-39 \%$ of the $\mathrm{CH}_{4}$ loss due to gas evasion and the remaining $61-74 \%$ a result of other $\mathrm{CH}_{4}$ sinks.

\section{Discussion}

$k_{600}$ model limitations for $\boldsymbol{k}_{\mathrm{CH} 4}$ and diffusive $\mathrm{CH}_{4}$ estimates

Accurately estimating $k_{\mathrm{CH} 4}$ for rivers and streams is of increasing importance as studies continue to show that fluvial systems tend to have higher $\mathrm{CH}_{4}$ concentrations than lakes, and the more turbulent conditions that characterize fluvial systems suggest that rivers and streams should be significant $\mathrm{CH}_{4}$ emitters. However, parameterizing $k$ for fluvial systems in general is still in its infancy. For our $\mathrm{CH}_{4}$ study, we chose a variety of gas exchange models based on studies of $\mathrm{CO}_{2}$ emissions and found some important differences between modelling diffusive $\mathrm{CO}_{2}$ and $\mathrm{CH}_{4}$ emissions.

As discussed by Raymond et al. (2012), river conditions and features that enhance turbulence, such as river velocity, slope and depth, promote higher piston velocities. The $k_{600}$ models that incorporated depth (R1, R2, and R7) and slope always produced the highest $k_{\mathrm{CH} 4}$ in our study; therefore, the sites that consistently had higher $k_{\mathrm{CH} 4}$ values were in the upstream section (sites 2-6) as they were $\sim 2 \mathrm{~m}$ shallower and $\sim 40 \%$ steeper (but only $\sim 50 \mathrm{~cm}$ elevation difference) than sites in the downstream section. Raymond et al. (2012), however, warns of the use of their depth-dependent models for larger stream orders as all of their models were derived from a low stream order dataset with an average depth of only $0.28 \mathrm{~m}$. As our study section was in a river of stream order 6 and ranged from $3 \mathrm{~m}$ to $5 \mathrm{~m}$ deep, perhaps the depth-dependent Raymond et al. (2012) models were not the most accurate for our system. 
Table 2. Seasonal and sectional $\mathrm{CH}_{4}$ mass balance results.

\begin{tabular}{|c|c|c|c|c|c|c|}
\hline \multicolumn{7}{|l|}{ Winter campaign 2012} \\
\hline Section 2-6 & 68.6 & 60.7 & 4.2 & -3.7 & 53 & 47 \\
\hline Section 6-8 (Saane River) & 60.7 & 59.7 & 0.8 & -0.3 & 75 & 25 \\
\hline Section 8-13 (Niederried/Aarberg) & 59.7 & 65.9 & 7.4 & 13.6 & - & - \\
\hline Total study area & - & - & 14.6 & -37.8 & 28 & 72 \\
\hline \multicolumn{7}{|l|}{ Spring campaign 2012} \\
\hline Section 1-2 (Wohlen dam) & 125.0 & 120.7 & 0.4 & -3.9 & 10 & 90 \\
\hline Section 2-6 & 120.7 & 113.8 & 5.0 & -1.9 & 73 & 27 \\
\hline Section 6-8 (Saane River) & 121.8 & 26.5 & 0.7 & -94.6 & 0.7 & 99.3 \\
\hline Section 8-13 (Niederried/Aarberg) & 26.5 & 82.4 & 5.1 & 61.0 & - & - \\
\hline Section 1-2 (Wohlen dam) & 214.8 & 208.4 & 0.9 & -5.5 & 14 & 86 \\
\hline Section 2-6 & 208.4 & 218.2 & 8.4 & 18.3 & - & - \\
\hline Section 6-8 (Saane River) & 226.7 & 105.8 & 1.4 & -119.5 & 1.2 & 98.8 \\
\hline Section 8-13 (Niederried/Aarberg) & 105.8 & 136.6 & 10.7 & 41.6 & - & - \\
\hline Section $13-15$ & 144.7 & 121.6 & 6.5 & -16.5 & 29 & 71 \\
\hline Total study area & - & - & 28.2 & -81.6 & 26 & 74 \\
\hline
\end{tabular}

*Dissolved $\mathrm{CH}_{4}$ into section.

${ }^{\dagger}$ Dissolved $\mathrm{CH}_{4}$ out of section.

${ }^{\ddagger} \mathrm{CH}_{4}$ mass transfer via surface diffusion.

${ }^{\S} \mathrm{Net} \mathrm{CH}_{4}$ mass balance; $\mathrm{nd}=$ no data.

However, the modelled $k_{\mathrm{CH} 4}$ values in our study do appear reasonable compared to values from empirical studies investigating piston velocities and diffusive $\mathrm{CH}_{4}$ emissions (Table 3 ). As well, the chamber-derived $k_{\mathrm{CH} 4}$ values, which are independent and empirically-derived estimates of $k_{\mathrm{CH} 4}$ that can be used to partially validate $k$ models, fell within the variability of the modelled $k_{\mathrm{CH} 4}$ values, agreeing best with models that included a depth term. Although in our case, the modeled $k_{\mathrm{CH} 4}$ values were based on $\mathrm{CO}_{2}$ emissions studies, while the chamberderived $k_{\mathrm{CH} 4}$ values were calculated from $\mathrm{CH}_{4}$ emissions. Other river and lake studies that have derived the piston velocity directly from chambers measuring both $\mathrm{CH}_{4}$ and $\mathrm{CO}_{2}$ found that $k_{\mathrm{CH} 4}$ is usually significantly higher than $k_{\mathrm{CO} 2}$, and attribute this to the low solubility of $\mathrm{CH}_{4}$ and its ability to form microscopic bubbles that contribute to total $\mathrm{CH}_{4}$ emissions collected in a chamber (Beaulieu et al. 2012; Prairie and del Giorgio 2013; Campeau et al. 2014; McGinnis et al. 2015). While we did not simultaneously measure $\mathrm{CO}_{2}$, we did find that the our chamber $k_{\mathrm{CH} 4}$ values were most similar to the highest modelled $k_{\mathrm{CH} 4}$ values, which were from the depth-dependent models that Raymond et al. (2012) cautioned against using to predict $\mathrm{CO}_{2}$ emissions from larger rivers. In other words, the $k_{\mathrm{CH} 4}$ calculated from the chamber measurements were on the high end of what would be expected for $k_{\mathrm{CO} 2}$. But since all of our chamber-derived $k_{\mathrm{CH} 4}$ results did fall within the variability of the modelled $k_{\mathrm{CH} 4}$ values (Fig. 3 ), perhaps the $\mathrm{CO}_{2}$-derived $k_{600}$ models are robust enough for estimating $k_{\mathrm{CH} 4}$, at least those models that include depth and produce the highest results.

Despite the fact that the $k_{\mathrm{CH} 4}$ values calculated from the chambers overlapped with the highest modelled $k$ values, only half of the chamber-captured $\mathrm{CH}_{4}$ emissions fell within the variability of $\mathrm{CH}_{4}$ emissions estimated with the models (Fig. 4c). In particular, the chamber that crossed the confluence was substantially higher than modelled emissions, suggesting that the $\mathrm{CO}_{2}$-derived $k_{600}$ models could not account for the true $\mathrm{CH}_{4}$ flux in that location. One explanation for this is that the $\mathrm{CO}_{2}$-derived $k$ models are indeed not sufficient for $\mathrm{CH}_{4}$ emission studies as the microbubble pathway, which potentially occurred at the confluence, does not exist for $\mathrm{CO}_{2}$ and would not be captured by $\mathrm{CO}_{2}$-derived gas exchange models. This will be discussed in more detail later, however.

\section{Spatial variability of Aare River $\mathrm{CH}_{4}$ dynamics downstream of Lake Wohlen}

Because of the limitations of the gas exchange models and the obvious variability between them, we did not 
Table 3. Minimum (min), average (avg) and maximum (max) piston velocity $\left(k_{\mathrm{CH} 4}\right)$ and areal diffusive $\mathrm{CH}_{4}$ estimates from other river and stream systems.

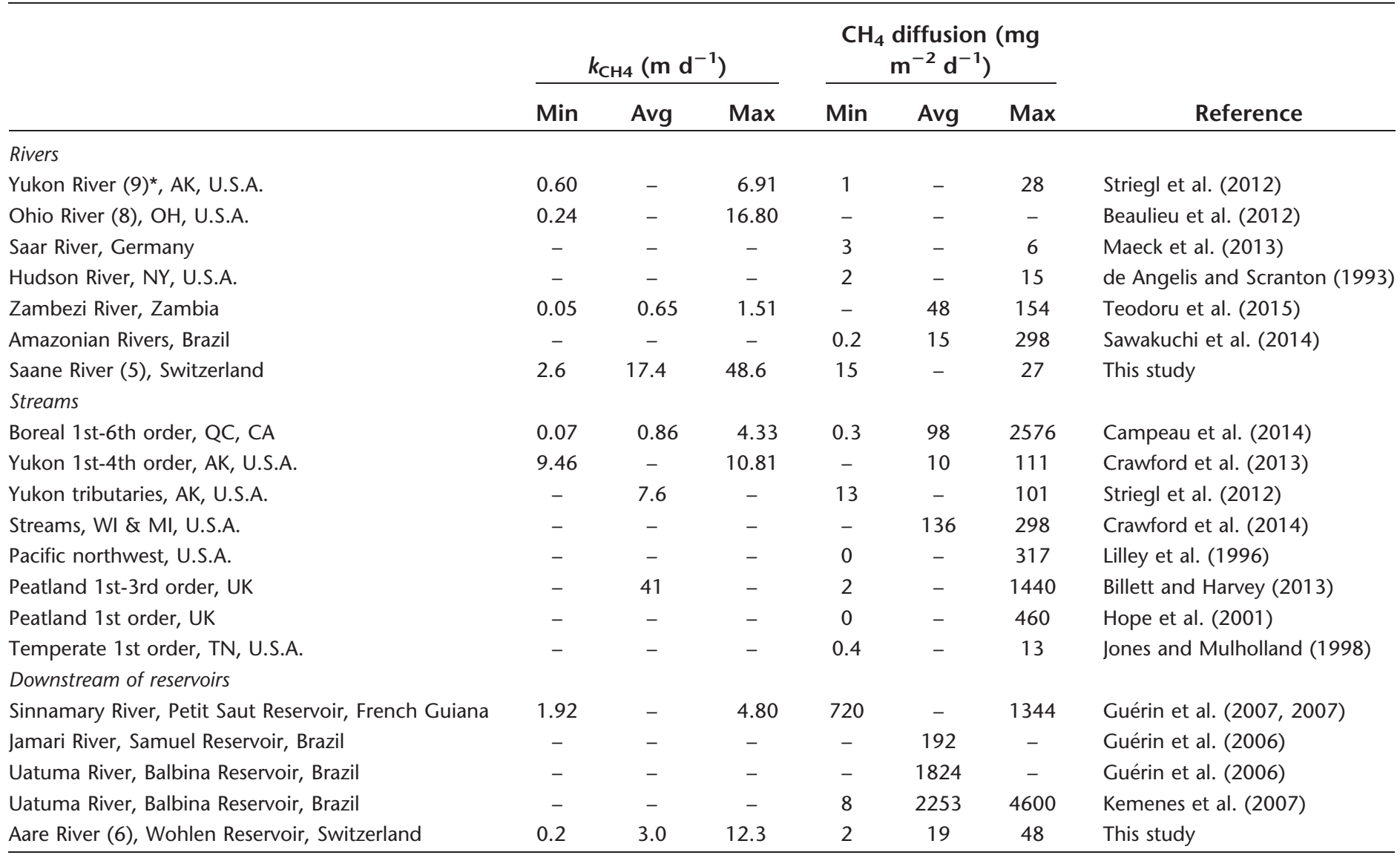

*Indicates stream order.

choose a single model to estimate diffusive $\mathrm{CH}_{4}$ emissions in the mass balance. Instead, we used the average of all the models and presented the mass balance variability based on individual models in Fig. 5 (as seen by the error bars). Overall, the mass balance results and the conclusions based on them were not greatly impacted by the $k_{\mathrm{CH} 4}$ and diffusive flux variability. For example, even when the $k_{\mathrm{CH} 4}$ model fluxes varied by a factor of four in the upstream section of the river (Fig. 3), $\Delta M$ varied only by a factor of two, and overall trends remained consistent. Gas exchange variability had the greatest effect on mass balance results when emission rates were highest, such as during the summer campaign, but the impact was not great and again overall trends remained the same. Ultimately, using the average of the modelled $k_{\mathrm{CH} 4}$ values was a robust procedure for the mass balance, and even when accounting for the flux variability resulting from the models, the sectional mass balance remained a useful tool for evaluating $\mathrm{CH}_{4}$ dynamics along the river.

The mass balance resulted in three major conclusions regarding the spatial variability of $\mathrm{CH}_{4}$ along this section of the Aare River downstream of a run-of-river reservoir: (1) Lake Wohlen dam releases the majority of its $\mathrm{CH}_{4}$ to the downstream reservoir with almost negligible degassing at the turbines; (2) the Saane River confluence was, unexpectedly, the local feature that most significantly impacted the $\mathrm{CH}_{4}$ dynamics along the river by causing a large decrease in dissolved $\mathrm{CH}_{4}$; and (3) the two smaller ROR dams downstream did not cause any noticeable decrease in dissolved $\mathrm{CH}_{4}$ transfer.

The $\mathrm{CH}_{4}$ dynamics of the upstream portion of our study area appears to have been dictated by the presence of the Wohlen reservoir as the concentrations at the sites up to $\sim 4 \mathrm{~km}$ downstream of the dam are similar to the $\mathrm{CH}_{4}$ concentrations in the reservoir (Fig. 2). According to the spring and summer mass balances, $\mathrm{CH}_{4}$ mass loss was almost negligible across Wohlen dam, likely because the dam intakes are located near the bottom of the reservoir resulting in only a $5 \mathrm{~m}$ decrease in elevation to the downstream river. The significantly higher $\mathrm{CH}_{4}$ concentrations below the dam and upstream of the Saane River inflow (Fig. 2b) translated into an average emission in the upstream section (between sites 2 
and 6) that was almost threefold higher than the average emission downstream of the tributary inflow in all three campaigns (Fig. 4).

Considering the high $k_{\mathrm{CH} 4}$ values and diffusive fluxes between the Wohlen dam and the tributary, the question is whether the dissolved $\mathrm{CH}_{4}$ leaving the reservoir had time to travel the $\sim 4 \mathrm{~km}$ to the Saane River where much of the dissolved $\mathrm{CH}_{4}$ was lost (discussed later), or whether there was another source in that river stretch resupplying dissolved $\mathrm{CH}_{4}$. A piston velocity (in units of depth per time) indicates the time in which a layer of water takes to equilibrate with the atmosphere. For example, the average $k_{\mathrm{CH} 4}$ for the upstream river section during the spring and summer campaigns of $4.2 \mathrm{~m} \mathrm{~d}^{-1}$ implies that $4.2 \mathrm{~m}$ of the water column will equilibrate with the atmosphere in one day. Since the average depth of the upstream river section is $3.2 \mathrm{~m}$, which is $\sim 75 \%$ of the spring and summer $k_{\mathrm{CH} 4}$ (i.e., $4.2 \mathrm{~m} \mathrm{~d}^{-1}$ ), then it should take $\sim 18$ h (i.e., $75 \%$ of $24 \mathrm{~h}$ ) for this portion of the river to completely degas. Based on the average dam discharge during the spring and summer campaigns $\left(159 \mathrm{~m}^{3}\right.$ $\mathrm{s}^{-1}$ ) and the volume of water flowing through the section (4 km length $\times 67 \mathrm{~m}$ width $\times 3.2 \mathrm{~m}$ depth), it only takes $\sim 90$ min for water to pass from the dam to the tributary. Thus, the $\mathrm{CH}_{4}$ leaving Wohlen dam has ample time to travel those $4 \mathrm{~km}$ downstream before degassing, and no other source is necessary to account for the constant $\mathrm{CH}_{4}$ concentrations along that section. Ultimately, the flow through conditions causing horizontal $\mathrm{CH}_{4}$ accumulation within the Wohlen ROR reservoir (DelSontro et al. 2010) sets up an ideal situation in which dissolved $\mathrm{CH}_{4}$ is rapidly transported downstream and enhances river $\mathrm{CH}_{4}$ emissions, despite the reservoir not stratifying and thus not forming an anoxic, $\mathrm{CH}_{4}$-rich hypolimnion that is the source of increased $\mathrm{CH}_{4}$ emissions downstream of other reservoir systems (Guérin et al. 2006; Kemenes et al. 2007).

Dissolved $\mathrm{CH}_{4}$ and emission dynamics along the portion of the Aare River between Lake Wohlen and Lake Biel diverge with a significant concentration and emission decrease at the Saane River confluence. The pronounced concentration difference observed there (between sites 6 and 8) during the winter and spring campaigns could have been the result of sampling unmixed waters (e.g., less $\mathrm{CH}_{4}$-enriched Saane River water) at site 8; however, the higher sampling resolution of the summer campaign shows that $\mathrm{CH}_{4}$ concentrations remained low below the confluence for at least another $5 \mathrm{~km}$ downstream. This finding, in addition to the fact that $\mathrm{CH}_{4}$ concentrations further than $5 \mathrm{~km}$ downstream during the winter and spring campaigns remained low, demonstrate that the significant $\mathrm{CH}_{4}$ decrease at the confluence of these two rivers was likely a true observation in each campaign. The implications and causes of this unexpected yet influential feature of the $\mathrm{CH}_{4}$ spatial heterogeneity along the Aare River is discussed in more detail later.
While diffusive $\mathrm{CH}_{4}$ emissions remained low following the Saane River confluence, the $\mathrm{CH}_{4}$ mass balance suggests that the $9 \mathrm{~km}$ section immediately downstream of the confluence, which includes two ROR dams, gained $\mathrm{CH}_{4}$. The river flows another $3 \mathrm{~km}$ following the confluence before encountering the first ROR reservoir, Niederried, which includes a shallow back-bay adjacent to the river that is ideal for methanogenesis and where ebullition has been observed but not quantified. Another $5.5 \mathrm{~km}$ downstream is the Aarberg dam of which no flooded regions are associated. A study in a dam-impacted German river that is similar to the Aare River found that sedimentation in front of ROR dams promotes methanogenesis, $\mathrm{CH}_{4}$ ebullition, and thus higher dissolved $\mathrm{CH}_{4}$ concentrations in front of those dams (Maeck et al. 2013). We did not survey for ebullition nor was our dissolved $\mathrm{CH}_{4}$ sampling conducted directly in front of the Niederried and Aarberg dams; therefore, we cannot conclude that increased rates of methanogenesis occurred in front of the dams, but this remains a viable explanation for the observed $\mathrm{CH}_{4}$ increase along that section. Regardless, our results suggest that these two small ROR dams did not likely cause significant degassing of the passing river water.

Importance of a confluence for river $\mathrm{CH}_{4}$ dynamics

During our investigation of the spatial variability of $\mathrm{CH}_{4}$ dynamics in the Aare River, we found that the confluence with the Saane River tributary had the most substantial impact on $\mathrm{CH}_{4}$ concentrations along our study area, particularly during the spring and summer campaigns in which the largest $\mathrm{CH}_{4}$ mass loss occurred across that confluence. The significant concentration decrease across the Saane inflow during the winter campaign (Fig. 2b), however, did not translate into a large $\mathrm{CH}_{4}$ mass loss in that section during that campaign (Fig. 5). The minor $\mathrm{CH}_{4}$ loss observed then was mostly a result of dilution by the Saane River as its discharge rate was higher than that of the Wohlen dam on that winter day. Since dilution by the Saane River was also considered in the $\mathrm{CH}_{4}$ mass transfer for the spring and summer campaigns, the substantial $\mathrm{CH}_{4}$ loss observed at the confluence must have been due to gas exchange and/or $\mathrm{CH}_{4}$ oxidation. According to the modelled diffusive fluxes, only $\sim 1 \%$ of the $\mathrm{CH}_{4}$ loss in the confluence section was due to air-water diffusive emissions (Table 2). This figure is raised to $\sim 8 \%$ when the diffusive fluxes measured during the summer drifting chamber deployment across the confluence are used in the mass balance, implying that the other $92 \%$ of the $\mathrm{CH}_{4}$ lost across the Saane confluence remains unaccounted for.

If gas exchange cannot explain the observed loss, then perhaps the loss was due to $\mathrm{CH}_{4}$ oxidation. Unfortunately, we did not measure $\mathrm{CH}_{4}$ oxidation rates in the Aare River, but we can calculate the rates necessary to oxidize the amount of $\mathrm{CH}_{4}$ lost across the confluence that was unaccounted for and compare that with literature values. Using the summer campaign data, we divided the $\mathrm{CH}_{4}$ lost that 
was unaccounted for $\left(99 \%=120 \mathrm{~kg} \mathrm{~d}^{-1}\right)$ by the volume of water in the section $\left(1.4 \times 10^{8} \mathrm{~L}\right)$, which yielded an oxidation rate $\left(\sim 53 \mu \mathrm{mol} \mathrm{L}{ }^{-1} \mathrm{~d}^{-1}\right)$ that was two orders of magnitude higher than the rate found in the Hudson River (0.66 $\mu$ mol L ${ }^{-1} \mathrm{~d}^{-1}$ ) - a system with similarly low $\mathrm{CH}_{4}$ concentrations $(0.9 \mu \mathrm{M})$ and experimentally-derived $\mathrm{CH}_{4}$ oxidation rates (de Angelis and Scranton 1993). Our calculated oxidation rate is comparable to estimates in other systems (Guérin and Abril 2007), but only to those with much higher $\mathrm{CH}_{4}$ concentrations. $\mathrm{CH}_{4}$ oxidation rates have been shown to be dependent on $\mathrm{CH}_{4}$ concentration, thus values from different systems are usually compared on the basis of first-order rate constants (in $\mathrm{d}^{-1}$ ), which is obtained by normalizing the oxidation rate by system concentration (Guérin and Abril 2007). At concentrations equivalent to just before the confluence during the summer campaign $(0.6 \mu \mathrm{M})$, the firstorder rate constant was $86 \mathrm{~d}^{-1}$, which is at least an order of magnitude higher than most of the published values, even those in systems with high $\mathrm{CH}_{4}$ concentrations (Guérin and Abril 2007). We, therefore, conclude that such a fast oxidation rate at this location is very unlikely in our system.

Considering there is no other biogeochemical process known to consume $\mathrm{CH}_{4}$ in freshwaters, we suggest that the $k_{600}$ models did not accurately account for all of the $\mathrm{CH}_{4}$ gas exchange that occurred at the Saane River inflow. Perhaps $\mathrm{CH}_{4}$ microbubbles (e.g., McGinnis et al. 2015) contributed to the observed gas loss at the confluence, which would not be constrained by the $k_{600}$ models for $\mathrm{CO}_{2}$. However, the $\mathrm{CH}_{4}$ fluxes from our drifting chamber experiment, which should have measured microbubbles, also did not account for the massive amount of $\mathrm{CH}_{4}$ lost at the confluence during the summer campaign. Perhaps a portion of the loss was due to microbubbles, but we propose that the majority of the loss was due to the additional turbulence that occurs at the meeting of two rivers. A confluence of rivers of this stream order can have enough force to modify the river bed (Rhoads and Kenworthy 1995), thus the turbulence experienced there may enhance gas emissions, similar to how rapids or waterfalls do (Hall et al. 2012; Teodoru et al. 2015) or the weir that was placed downstream of Petit Saut reservoir (Abril et al. 2005). This type of turbulence is likely also not constrained by the gas exchange models we used for our estimates. In regards to the drifting chambers also not constraining these emissions, we expect the emissions at a confluence to be as heterogeneous as other features of river confluences (Rhoads and Kenworthy 1995), thus our drifting chambers may have missed some crucial emission hot spots across the $60 \mathrm{~m}$ wide section of river. Regardless, the most likely explanation for the $\mathrm{CH}_{4}$ loss at the Aare-Saane river confluence is a combination of oxidation and enhanced gas emissions, with gas exchange most likely being the dominant cause for the observed loss. Ultimately, river confluences appear to be interesting features that impact river $\mathrm{CH}_{4}$ dynamics and deserve more attention when investigating spatial heterogeneity of $\mathrm{CH}_{4}$ emissions, especially as they are not included in current river gas exchange models. Missing a confluence altogether due to under sampling could lead to significant underestimations of river $\mathrm{CH}_{4}$ emissions.

\section{River $\mathrm{CH}_{4}$ emissions downstream of a ROR reservoir}

Despite the variability in modelled diffusive estimates and the fact that the $k_{600}$ models may not have accounted for $\mathrm{CH}_{4}$ gas exchange at the Saane River inflow, the $\mathrm{CH}_{4}$ mass balance along the river followed consistent patterns and the ultimate conclusions remained the same. Overall, there was a net $\mathrm{CH}_{4}$ loss along the entire Aare River study area in each campaign (Table 2), which was due to a combination of gas exchange and oxidation. Although Aare River $\mathrm{CH}_{4}$ concentrations were lower relative to other reservoirs (Guérin et al. 2006; Kemenes et al. 2007), the contribution of modelled diffusive emissions and other sinks such as oxidation (albeit, at the confluence it was more missing gas exchange) to the total $\mathrm{CH}_{4}$ loss observed in the Aare River (26-39\% diffusion, 6174\% other sinks; Table 2) falls between contributions from other notable studies. Kemenes et al. (2007) found downstream of Balbina reservoir (Brazil) that $15 \%$ of the inflowing $\mathrm{CH}_{4}$ was diffused and $85 \%$ was oxidized, while Guérin and Abril (2007) found that 50\% of the $\mathrm{CH}_{4}$ flowing downstream from Petit Saut reservoir (French Guiana) was emitted to the atmosphere and $40 \%$ was oxidized. Our estimates, however, do not include the contribution of possibly unaccounted for gas exchange at the Saane inflow during spring and summer, which would undoubtedly increase the contribution from gas exchange to the $\mathrm{CH}_{4}$ loss along the Aare River.

While the percentage of inflowing $\mathrm{CH}_{4}$ that diffused from the Aare River was similar to that from other downstream reservoir systems, diffusion rates in the Aare River were up to two orders of magnitude lower than emissions from rivers downstream of some large South American reservoirs (Table 3). The Wohlen reservoir is significantly smaller than those South American reservoirs and it does not form an anoxic, $\mathrm{CH}_{4}$-rich hypolimnion, which was likely fueling the high $\mathrm{CH}_{4}$ concentrations and diffusion rates in the downstream river systems of the South American reservoirs (Guérin et al. 2006; Kemenes et al. 2007). Overall, compared to tropical rivers and other reservoir systems, diffusive $\mathrm{CH}_{4}$ emission rates from the Aare River are rather low. While the river $\mathrm{CH}_{4}$ emissions in our study are also low compared to temperature and northern streams, they are slightly higher than rivers of equivalent size and stream order in similar regions, including its own smaller tributary, the Saane River (Table 3).

Seasonal daily diffusive $\mathrm{CH}_{4}$ emissions (in $\mathrm{kg} \mathrm{d}^{-1}$ ) from the Aare River (see "Total study area" in Table 2) were an order of magnitude higher than daily emissions upscaled to the $0.33 \mathrm{~km}^{2}$ Wohlen dam basin $\left(2.1,3.2\right.$ and $2.3 \mathrm{~kg} \mathrm{~d}^{-1}$ during winter, spring and summer campaigns, respectively). In order to compare emissions from the $1.4 \mathrm{~km}^{2}$ Aare River study area to total emissions from the entire $2.5 \mathrm{~km}^{2}$ Wohlen reservoir, 
we must use the average daily emission rate $\left(200 \mathrm{~kg} \mathrm{~d}^{-1}\right)$ reported in previously published work on the reservoir in which ebullitive $\mathrm{CH}_{4}$ emissions in the reservoir were also quantified (DelSontro et al. 2010). We found that the Aare River diffusive emissions (average of three seasonal campaigns, $19 \mathrm{~kg} \mathrm{~d}^{-1}$ ) are in fact an order of magnitude less than emissions from the entire bubbling reservoir; therefore, when Aare River emissions are attributed to the reservoir, they contribute only $9 \%$ to total $\mathrm{CH}_{4}$ emissions from the reservoir. Guérin et al. (2006), who also quantified ebullition in reservoirs, found some similar and some higher values for downstream diffusive emission contributions of various South American reservoirs (9-33\%, 23\% and 5\% for the Petit Saut, Balbina, and Samuel reservoirs, respectively). Kemenes et al. (2007) and Deshmukh et al. (2016) similarly found small contributions of downstream diffusive river emissions relative to the upstream reservoirs (7\% and 10-33\%, respectively).

Seeing as the Saane inflow would likely reset the $\mathrm{CH}_{4}$ dynamics of the Aare River regardless of the presence of Wohlen dam, the $\mathrm{CH}_{4}$ emissions from the Aare River below the Saane confluence should perhaps not be attributed to the Wohlen reservoir. Thus, diffusive $\mathrm{CH}_{4}$ emissions from only the $\sim 4 \mathrm{~km}$ between the Wohlen dam and the Saane inflow would constitute a mere $3 \%$ of the total emissions attributed to the Wohlen reservoir, as opposed to $9 \%$. If additional gas exchange that was not taken into account in the $k_{600}$ models occurred at the Aare-Saane confluence (as opposed to $\mathrm{CH}_{4}$ oxidation), then river emissions attributed to the reservoir would be significantly higher. While we do suggest that a portion of the upstream Aare River $\mathrm{CH}_{4}$ emissions are partly due to the presence of the Wohlen reservoir, we also recognize the fact that rivers can naturally accumulate and emit $\mathrm{CH}_{4}$ (Table 3). Thus, since we do not know pre-dam $\mathrm{CH}_{4}$ emissions from the Aare River, we cannot provide a definitive value for the impact the reservoir has had on total $\mathrm{CH}_{4}$ emissions from the entire area. Regardless, $\mathrm{CH}_{4}$ emissions downstream from ROR reservoirs can be enhanced, albeit perhaps not as dramatically as in other types of reservoir systems. However, since a large portion of the world's rivers are fragmented by small ROR dams, these features should be taken into consideration when estimating local, regional, and global $\mathrm{CH}_{4}$ emissions from inland waters. Moreover, natural heterogeneities in river courses like confluences with other rivers may cause significant spatial variability in $\mathrm{CH}_{4}$ concentrations and potentially emissions, and thus such river features should also be accounted for when evaluating $\mathrm{CH}_{4}$ dynamics in rivers.

\section{References}

Abril, G., and others. 2005. Carbon dioxide and methane emissions and the carbon budget of a 10-year old tropical reservoir (Petit Saut, French Guiana). Global Biogeochem. Cycles. 19: GB4007, doi:10.1029/2005GB002457
Alin, S. R., M. D. F. F. L. Rasera, C. I. Salimon, J. E. Richey, G. W. Holtgrieve, A. V. Krusche, and A. Snidvongs. 2011. Physical controls on carbon dioxide transfer velocity and flux in low-gradient river systems and implications for regional carbon budgets. J. Geophys. Res. 116: G01009, doi: 10.1029/2010JG001398

Aufdenkampe, A. K., E. Mayorga, P. A. Raymond, J. M. Melack, S. C. Doney, S. R. Alin, R. E. Aalto, and K. Yoo. 2011. Riverine coupling of biogeochemical cycles between land, oceans, and atmosphere. Front. Ecol. Environ. 9: 53-60. doi:10.1890/100014

Barros, N., J. J. Cole, L. J. Tranvik, Y. T. Prairie, D. Bastviken, V. L. M. Huszar, P. del Giorgio, and F. Roland. 2011. Carbon emission from hydroelectric reservoirs linked to reservoir age and latitude. Nat. Geosci. 4: 593-596. doi: $10.1038 /$ ngeo 1211

Bastviken, D., L. J. Tranvik, J. A. Downing, P. M. Crill, and A. Enrich-Prast. 2011. Freshwater methane emissions offset the continental carbon sink. Science 331: 50. doi: 10.1126/science. 10096808

Battin, T. J., S. Luyssaert, L. A. Kaplan, A. K. Aufdenkampe, A. Richter, and L. J. Tranvik. 2009. The boundless carbon cycle. Nat. Geosci. 2: 598-600. doi:10.1038/ngeo618

Beaulieu, J. J., W. D. Shuster, and J. A. Rebholz. 2012. Controls on gas transfer velocities in a large river. J. Geophys. Res. Biogeosciences. 117: G02007. doi:10.1029/2011JG0 01794

Billett, M. F., and F. H. Harvey. 2013. Measurements of CO2 and $\mathrm{CH} 4$ evasion from UK peatland headwater streams. Biogeochemistry. 114: 165-181. doi:10.1007/s10533-0129798-9

Borges, A. V., J. P. Vanderborght, L. S. Schiettecatte, F. Gazeau, S. Ferrón-Smith, B. Delille, and M. Frankignoulle. 2004. Variability of the gas transfer velocity of CO2 in a macrotidal estuary (the Scheldt). Estuaries. 27: 593-603. doi:10.1007/BF02907647

Campeau, A., J. F. Lapierre, D. Vachon, and P. A. del Giorgio. 2014. Regional contribution of $\mathrm{CO} 2$ and $\mathrm{CH} 4$ fluxes from the fluvial network in a lowland boreal. Global Biogeochem. Cycles. 28: 57-69. doi:10.1002/2013 GB004685

Ciais, P., and others. 2013. Carbon and Other Biogeochemical Cycles, p. 465-570. In T.F. Stocker, D. Qin, G.-K. Plattner, M. Tignor, S. Allen, J. Boschung, A. Nauels, Y. Xia, V. Bex, and P. Midgley [eds.], Climate change 2013: the physical science basis. Contribution of working group I to the fifth assessment report of the intergovernmental panel on climate change. Cambridge University Press.

Cole, J. J., and others. 2007. Plumbing the global carbon cycle: Integrating inland waters into the terrestrial carbon budget. Ecosystems. 10: 172-185. doi:10.1007/s10021-006-9013-8

Crawford, J. T., R. G. Striegl, K. P. Wickland, M. M. Dornblaser, and E. H. Stanley. 2013. Emissions of carbon 
dioxide and methane from a headwater stream network of interior Alaska. J. Geophys. Res. Biogeosciences. 118: 482-494. doi:10.1002/jgrg.20034

Crawford, J. T., N. R. Lottig, E. H. Stanley, J. F. Walker, P. C. Hanson, J. C. Finlay, and R. G. Striegl. 2014. CO2 and $\mathrm{CH} 4$ emissions from streams in a lake-rich landscape: Patterns, controls, and regional significance. Glob. Biogeochem. Cycleso. 28: 197-210. doi:10.1002/ 2013GB004661

Crusius, J., and R. Wanninkhof. 2003. Gas transfer velocities measured at low wind speed over a lake. Limnol. Oceanogr. 48: 1010-1017. doi:10.4319/1o.2003.48.3.1010

de Angelis, M. A., and M. I. Scranton. 1993. Fate of methane in the Hudson river and estuary. Global Biogeochem. Cycles. 7: 509-523. doi:10.1029/93GB01636

DelSontro, T., D. F. McGinnis, S. Sobek, I. Ostrovsky, and B. Wehrli. 2010. Extreme methane emissions from a Swiss hydropower reservoir: Contribution from bubbling sediments. Environ. Sci. Technol. 44: 2419-2425. doi: 10.1021/es9031369

Deshmukh, C., and others. 2016. Low methane (CH4) emissions downstream of a monomictic subtropical hydroelectric reservoir (Nam Theun 2, Lao PDR). Biogeosciences. 13: 1919-1932. doi:10.5194/bgd-12-11313-2015

Eugster, W., T. DelSontro, and S. Sobek. 2011. Eddy covariance flux measurements confirm extreme $\mathrm{CH} 4$ emissions from a Swiss hydropower reservoir and resolve their shortterm variability. Biogeosciences. 8: 2815-2831. doi: 10.5194/bg-8-2815-2011

Giles, J. 2006. Methane quashes green credentials of hydropower. Nature. 444: 524-525. doi:10.1038/444524a

Guérin, F., G. Abril, S. Richard, B. Burban, C. Reynouard, P. Seyler, and R. Delmas. 2006. Methane and carbon dioxide emissions from tropical reservoirs: Significance of downstream rivers. Geophys. Res. Lett. 33: L21407, doi: 10.1029/2006GL027929

Guérin, F., and G. Abril. 2007. Significance of pelagic aerobic methane oxidation in the methane and carbon budget of a tropical reservoir. J. Geophys. Res. 112: G03006, doi: 10.1029/2006JG000393

Guérin, F., G. Abril, D. Serça, C. Delon, S. Richard, R. Delmas, A. Tremblay, and L. Varfalvy. 2007. Gas transfer velocities of $\mathrm{CO} 2$ and $\mathrm{CH} 4$ in a tropical reservoir and its river downstream. J. Mar. Syst. 66: 161-172. doi:10. 1016/j.jmarsys.2006.03.019

Guérin, F., G. Abril, A. de Junet, and M. P. Bonnet. 2008. Anaerobic decomposition of tropical soils and plant material: Implication for the $\mathrm{CO} 2$ and $\mathrm{CH} 4$ budget of the Petit Saut Reservoir. Appl. Geochemistry. 23: 2272-2283. doi: 10.1016/j.apgeochem.2008.04.001

Hall, R. O., T. A. Kennedy, and E. J. Rosi-Marshall. 2012. Airwater oxygen exchange in a large whitewater river. Limnol. Oceanogr. Fluids Environ. 2: 1-11. doi:10.1215/ 21573689-1572535
Hope, D., S. M. Palmer, M. F. Billett, and J. J. C. Dawson. 2001. Carbon dioxide and methane evasion from a temperate peatland stream. Limnol. Oceanogr. 46: 847-857. doi:10.4319/lo.2001.46.4.0847

Jähne, B. J., K. O. M. Münnich, R. Bösinger, A. Dutzi, W. Huber, and P. Libner. 1987. On the Parameters Influencing Air-Water Gas Exchange. J. Geophys. Res. 92: 19371949. doi:10.1029/JC092iC02p01937

Jones, J. B., and P. J. Mulholland. 1998. Methane input and evasion in a hardwood forest stream: Effects of subsurface flow from shallow and deep flowpaths. Limnol. Oceanogr. 43: 1243-1250. doi:10.4319/lo.1998.43.6.1243

Kemenes, A., B. R. Forsberg, and J. M. Melack. 2007. Methane release below a tropical hydroelectric dam. Geophys. Res. Lett. 34: L12809, doi:10.1029/2007GL029479

Lilley, M. D., M. A. DeAngelis, and E. J. Olson. 1996. Methane concentrations and estimated fluxes from Pacific Northwest rivers. Mitt. Internat. Verein. Limnol. 25: 187-196.

Lorke, A., and others. 2015. Technical note: Drifting versus anchored flux chambers for measuring greenhouse gas emissions from running waters. Biogeosciences. 12: 70137024. doi:10.5194/bg-12-7013-2015

MacIntyre, S., R. Wanninkhof, and J. P. Chanton. 1995. Trace gas exchange across the air-water interface in freshwater and coastal marine environments, p. 52-97 In Biogenic trace gases: Measuring emissions from soil and water. Wiley-Blackwell.

Maeck, A., T. Delsontro, D. F. McGinnis, H. Fischer, S. Flury, M. Schmidt, P. Fietzek, and A. Lorke. 2013. Sediment trapping by dams creates methane emission hot spots. Environ. Sci. Technol. 47: 8130-8137. doi:10.1021/es4003907

McAullife, C. 1979. GC determination of solutes by multiple phase equilibration. Chem Tech. 1: 46-51.

McGinnis, D. F., G. Kirillin, K. W. Tang, S. Flury, P. Bodmer, C. Engelhardt, P. Casper, and H. Grossart. 2015. Enhancing Surface Methane Fluxes from an Oligotrophic Lake: Exploring the Microbubble Hypothesis. Environ. Sci. Technol. 49: 873-880. doi:10.1021/es503385d

Nilsson, C., C. A. Reidy, M. Dynesius, and C. Revenga. 2005. Fragmentation and flow regulation of the world's large river systems. Science. 308: 405-408. doi:10.1126/ science. 1107887

Prairie, Y. T., and P. A. del Giorgio. 2013. A new pathway of freshwater methane emissions and the putative importance of microbubbles. Inl. Waters 3. 311-320. doi: 10.5268/iw. -3.3 .542$

Raymond, P. A., and others. 2012. Scaling the gas transfer velocity and hydraulic geometry in streams and small rivers. Limnol. Oceanogr. Fluids Environ. 2: 41-53. doi: 10.1215/21573689-1597669

Raymond, P. A., and others. 2013. Global carbon dioxide emissions from inland waters. Nature. 503: 355-359. doi: $10.1038 /$ nature 12760 
Rhoads, B. L., and S. T. Kenworthy. 1995. Flow structure at an asymmetrical stream confluence. Geomorphology. 11: 273-293. doi:10.1016/0169-555X(94)00069-4

Sawakuchi, H. O., D. Bastviken, A. O. Sawakuchi, A. V. Krusche, M. V. R. Ballester, and J. E. Richey. 2014. Methane emissions from Amazonian Rivers and their contribution to the global methane budget. Glob. Chang. Biol. 20: 2829-2840. doi:10.1111/gcb.12646

Schubert, C. J., T. Diem, and W. Eugster. 2012. Methane emissions from a small wind shielded lake determined by eddy covariance, flux chambers, anchored funnels, and boundary model calculations: A comparison. Environ. Sci. Technol. 46: 4515-4522. doi:10.1021/es203465x

Selvam, B. P., S. Natchimuthu, L. Arunachalam, and D. Bastviken. 2014. Methane and carbon dioxide emissions from inland waters in India - Implications for large scale greenhouse gas balances. Glob. Chang. Biol. 20: 33973407. doi:10.1111/gcb.12575

St. Louis, V. L., C. A. Kelly, É. Duchemin, J. W. M. Rudd, and D. M. Rosenberg. 2000. Reservoir surfaces as sources of greenhouse gases to the atmosphere: A global estimate. Bioscience. 50: 766-775. doi:10.1641/0006-3568(2000) 050[0766:RSASO

Stanley, E. H., N. J. Casson, S. T. Christel, J. T. Crawford, L. C. Loken, and S. Oliver. 2016. The ecology of methane in streams and rivers: Patterns, controls, and global significance. Ecol. Monogr. 86: 146-171. doi:10.1890/15-1027

Striegl, R. G., M. M. Dornblaser, C. P. McDonald, J. R. Rover, and E. G. Stets. 2012. Carbon dioxide and methane emissions from the Yukon River system. Global Biogeochem. Cycles. 26: GB0E05, doi:10.1029/2012GB004306

Syvitski, J. P. M., C. J. Vorosmarty, A. J. Kettner, and P. Green. 2005. Impact of humans on the flux of terrestrial sediment to the global coastal ocean. Science. 308: 376380. doi:10.1126/science.1109454

Teodoru, C. R., P. A. del Giorgio, Y. T. Prairie, and M. Camire. 2009. Patterns in pCO2 in boreal streams and rivers of northern Quebec, Canada. Global Biogeochem. Cycles. 23: GB2012. doi:10.1029/2008GB003404

Teodoru, C. R., F. C. Nyoni, A. V. Borges, F. Darchambeau, I. Nyambe, and S. Bouillon. 2015. Dynamics of greenhouse gases (CO2, CH4, N2O) along the Zambezi River and major tributaries, and their importance in the riverine carbon budget. Biogeosciences 12: 2431-2453. doi: 10.5194/bg-12-2431-2015

Tranvik, L. J., and others. 2009. Lakes and reservoirs as regulators of carbon cycling and climate. Limnol. Oceanogr. 54: 2298-2314. doi:10.4319/1o.2009.54.6_part_2.2298
Tremblay, A., L. Varfalvy, C. Roehm, and M. Garneau. 2005. Greenhouse gas Emissions - Fluxes and processes, Springer.

Vachon, D., Y. T. Prairie, and J. J. Cole. 2010. The relationship between near-surface turbulence and gas transfer velocity in freshwater systems and its implications for floating chamber measurements of gas exchange. Limnol. Oceanogr. 55: 1723-1732. doi:10.4319/lo.2010.55.4.1723

Vachon, D., and Y. T. Prairie. 2013. The ecosystem size and shape dependence of gas transfer velocity versus wind speed relationships in lakes. Can. J. Fish. Aquat. Sci. 70: 8-1. doi:10.1139/cjfas-2013-0241

Vörösmarty, C. J., M. Meybeck, B. Fekete, K. Sharma, P. Green, and J. P. Syvitski. 2003. Anthropogenic sediment retention: major global impact from registered river impoundments. Glob. Planet. Change. 39: 169-190. doi: 10.1016/S0921-8181(03)00023-7

Wanninkhof, R. 2014. Relationship between wind speed and gas exchange over the ocean. Limnol. Oceanogr.: Methods. 12: 351-362. doi:10.4319/lom.2014.12.351

Wehrli, B. 2011. Climate science: Renewable but not carbonfree. Nat. Geosci. 4: 585-586. doi:10.1038/ngeo1226

Wiesenburg, D. A., and N. L. Guinasso. 1979. Equilibrium solubilities of methane, carbon monoxide, and hydrogen in water and sea water. J. Chem. Eng. Data. 24: 356-360. doi:10.1021/je60083a006

\section{Acknowledgments}

We thank Alois Zwyssig and Christian Dinkel for help in the field, Pascal Niklaus (University of Zurich) and Dominic Vachon (UQAM) for important discussions, Serge Robert and the late Gijs Nobbe for help with lab analyses, Diego Sanchez Cristo for help with statistical analyses, and HSC for the hope. We also thank P. Armin, B. German, P. Vonlanthen A. Gilli, and F. Anselmetti for use of field supplies, and three anonymous reviewers for their suggestions that significantly improved this manuscript. This work was funded via a Swiss Government Excellence Scholarship for Foreign Scholars awarded to Karina Perez by the Federal Commission for Scholarships for Foreign Students (FCS), as well as funds from Eawag (Swiss Federal Institute of Aquatic Science and Technology), ETH Zurich, and the éLEMO Project.

\section{Conflict of Interest}

None declared.

Submitted 03 September 2015 Revised 04 March 2016; 22 June 2016 Accepted 14 July 2016

Associate editor: Kimberly Wickland 